\title{
A model for rockfill compressibility
}

\author{
L. A. OLDECOP* and E. E. ALONSO*
}

The paper presents a macroscopic constitutive model for rockfill that includes the effect of water on compressibility and collapse phenomena. Breakage of rock particles and fracture propagation are basic underlying mechanisms controlled by the relative humidity of the air filling the rockfill voids. A conceptual deformation model based on these mechanisms is first proposed and discussed. The results of oedometer tests on a quartzitic slate rockfill, in which the air relative humidity was controlled, are then presented. A significant finding is that bringing the relative humidity within the specimen to its maximum $(100 \% \mathrm{RH})$ leads to a collapse strain equal to that observed in flooded specimens. An elastoplastic constitutive model, consistent with the basic deformation framework, is developed. Its parameters have a clear physical meaning. Guidelines for parameter determination are given. Model performance is finally compared with the results of the experimental programme.

KEYWORDS: compaction; compressibility; constitutive relations; gravels; laboratory tests; partial saturation.
Larticle présente un modèle macroscopique de comportement des matériaux d'enrochement. Il prend en compte l'influence de l'eau sur les phénomènes de compressibilité et de collapse. Les mécanismes fondamentaux sous-jacents considérés sont le broyage et la propagation de la fracture à l'intérieur des particules, controllés par l'humidité relative de l'air remplissant les vides du matériau d'enrochement. Un modéle conceptuel de déformation est premièrement proposé et discuté sur la base de ces mécanismes. Des résultats d'essais oedométriques à humidité relative contrôlée réalisés sur des enrochements d'ardoise quartzitique sont ensuite présentés. Un résultat important est le fait que la déformation de collapse obtenue par augmentation de l'humidité relative jasqu'à une valeur de $100 \%$ est la même que celle observée par inondation de l'échantillon. Un modèle élastoplastique cohérent avec le cadre conceptuel de déformation proposé est alors développé. Ses paramètres ont une signification physique claire et la démarche pour les obtenir est donnée. Les prédictions du modèle sont comparées avec les résultats du programme expérimental.

\section{INTRODUCTION}

The use of rockfill as a construction material started during the second half of the nineteenth century with the building of timber-faced mining dams in California (Penman, 1992). Since then, and essentially in connection with the construction and operation of large rockfill dams in the twentieth century, a large number of field observations concerning rockfill behaviour have been collected. Rockfill exhibits a slow accumulation of deformation over many decades (Sowers et al., 1965). When upstream shells of zoned earthdams are submerged, a collapse is often observed. Downstream shells also collapse after rainfall (Marsal et al., 1976; Naylor et al., 1997), a behaviour that is difficult to explain with the current understanding of rockfill deformation mechanisms.

Terzaghi (1960) suggested that a possible reason for the large deformations of rockfills could be the breakage of rock particles in the vicinity of highly stressed contacts and the subsequent rearrangement of the granular structure into a more stable position.

During the 1960s and 1970s, much effort was put into testing rockfill samples in the laboratory. Large-scale testing equipment was developed in some research centres (Sowers et al., 1965; Fumagalli, 1969; Marachi et al., 1969; Marsal, 1973; Penman \& Charles, 1976; Veiga Pinto, 1983), and all types of classical soil mechanics tests were carried out. The clear conclusion that arises from all this experimental work is that the main cause of the distinct rockfill behaviour is particle breakage, a phenomenon that seems to be enhanced by the presence of water.

Nobari \& Duncan (1972) carried out a systematic investigation of the factors that influence the collapse of rockfill upon flooding. Their work included one-dimensional and triaxial compression tests on crushed argillite. They found that the initial water content was the most important factor determining the amount of collapse upon flooding: the larger the initial water content, the smaller was the collapse deformation. Sieve

Manuscript received 24 May 1999; revised manuscript accepted 3 May 2000

Discussion on this paper to reach editor by 6 September 2001, for further details see inside front cover

* Department of Geotechnical Engineering and Geosciences, Universitat Politecnica de Catalunya, Barcelona, Spain. analysis carried out before and after flooding the sample showed that during collapse some particle crushing occurs. This observation suggests that the reduction of rock strength due to wetting may be the mechanism that determines the collapse behaviour.

Some researchers (Sowers et al., 1965; Marsal, 1973; Clements, 1981) tested isolated rock particles and rock points under compression. In constant-loading tests, Clements (1981) observed time-dependent deformation of contacts. When, after a certain time under constant load, the contact was flooded, additional displacements (also delayed in time) occurred. Clements' results for isolated contacts are compared in Fig. 1 with the results of oedometer tests reported by Sowers et al. (1965). The parallel behaviour between both types of test suggests that time-dependent strains and collapse of rockfills are both closely related to the particle breakage phenomenon.

The aim of this paper is to present a macroscopic constitutive model for rockfill stress-strain behaviour, consistent with previous experiences and with more recent experimental results, which are also presented and discussed in the paper. A basic mechanism of rockfill volumetric deformation that is based on a fracture propagation mechanism is first proposed. This deformation mechanism is able to give a qualitative physical explanation of time-dependent strains and collapse strains of rockfill, and of their simultaneous dependence on stress and water action.

Rockfill can be considered as having two sets of voids. A set of large voids is formed by the inter-particle spaces. Rock particles have their own natural porosity, and hence a second set of very much smaller voids can be identified within the rock particles. In order to avoid confusion, the following large interparticle voids will be termed rockfill voids, while the term rock pores will be used to refer to the small pores within the rock particles. In the latter group, only open pores are considered (i.e. those connected with the rockfill voids). The experimental observations mentioned suggest that the action of water contained within the rock pores has a determinant role on rockfill deformation. It was thought that tests in which the water content of rock pores could be controlled would provide a better insight into rockfill behaviour. Such tests were performed on a rockfilltype material using a relative humidity control technique. Their results are interpreted in terms of the proposed conceptual model in the third part of this paper. 


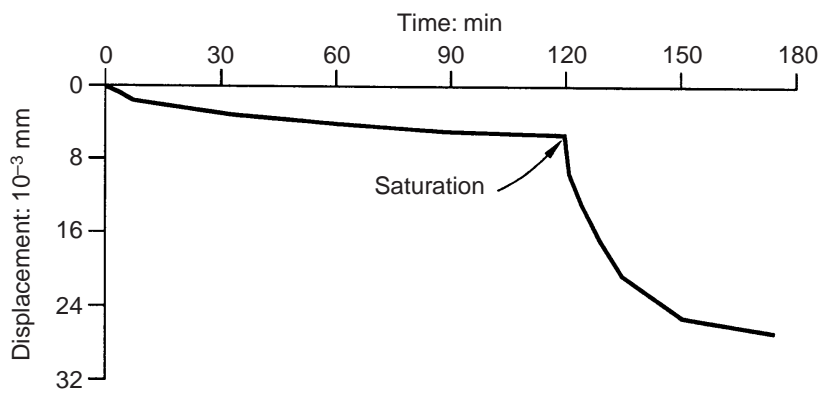

(a)

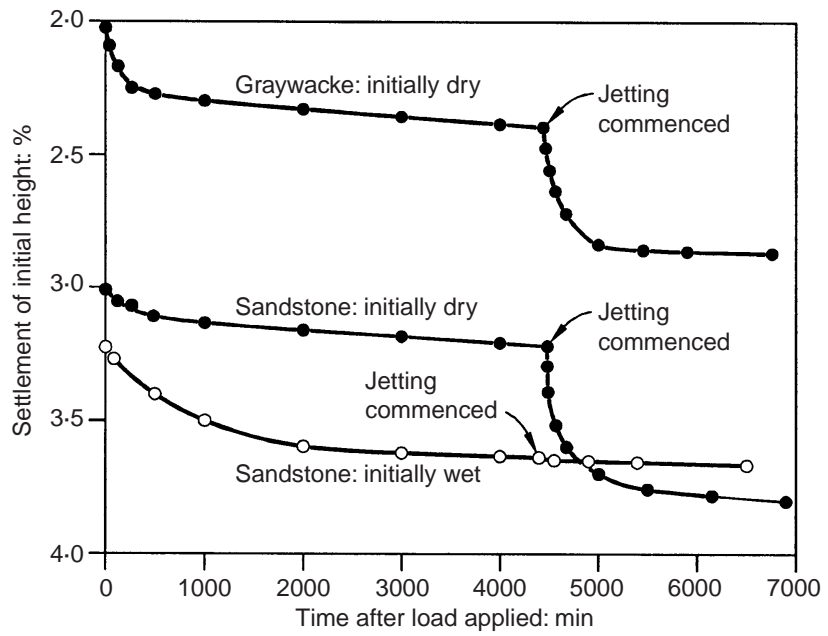

(b)

Fig. 1. (a) Effect of saturation in contact test of shaped point; contact angle $169 \cdot 1^{\circ}$ (after Clements, 1981). (b) Effect of jetting dry rockfill under load and of initial wetting on settlement at $16300 \mathrm{psf}$ in oedometer tests (after Sowers et al., 1965)

On the basis of the experimental results and the proposed deformation mechanism, a constitutive model for the compressibility of rockfill that takes into account the influence of water is then proposed. It includes the mechanisms of rockfill deformation in an elastoplastic framework. In this way, an overall macroscopic constitutive model is developed. The proposed model and the comparison between test results and model performance focus on volumetric deformations. Behaviour under deviatoric stress changes lay outside the scope of the paper. It is believed, however, that the framework developed provides a convenient basis for its extension to generalized stress states.

\section{A CONCEPTUAL MODEL FOR ROCKFILL VOLUMETRIC DEFORMATION}

Among the reported water-induced phenomena leading to particle breakage [loss of cohesion due to mineral superficial energy reduction (Vutukuri \& Lama, 1978); suction reduction (Vutukuri \& Lama, 1978); expansion of clay minerals (De Alba \& Sesana, 1978; Delgado et al., 1982)], the subcritical crack propagation due to stress corrosion (Atkinson \& Meredith, 1987) offers a comprehensive explanation of rockfill behaviour.

Any flaw in a piece of rock acts as a stress concentrator, and can initiate a crack that propagates under the action of load and also under the action of water. The stress intensity factor, as defined in linear elastic fracture mechanics (LEFM) (Broek, 1985), allows the complete characterization of the stress field in the crack tip vicinity. It embodies the influence of the crack length, the applied load, the geometry and the size of the body containing the crack, and can be computed with the following general expression (Broek, 1985):

$$
K_{L}=\beta \sigma \sqrt{\pi a}
$$

where $\sigma$ is the stress far from the crack influence zone, $a$ is the length of the crack, and $\beta$ is a dimensionless factor that depends on the geometry of the body: that is, the shape and the ratio $a / D$, where $D$ is a generalized size parameter. The subscript $L$ denotes the crack load mode: tensile, mode I; shear normal to crack tip, mode II; and shear parallel to crack tip, mode III. For many simple geometries, the factor $\beta$ can be obtained from handbooks (Murakami, 1987).

The value of $K_{L}$ that marks the onset of crack propagation for a given material is called the fracture toughness, $K_{L \mathrm{c}}$, and can be obtained for each load mode $L$ from suitable tests. In terms of LEFM, while $K_{L}<K_{L \mathrm{c}}$ the crack does not grow at all, and when $K_{L} \geqslant K_{L \mathrm{c}}$ a catastrophic propagation occurs. Crack propagation mechanisms in pure mode I (tension) are by far the most studied by experimental and theoretical work. In the following discussion, we shall refer to experimental results that were obtained mostly for mode I loaded cracks. However, there is no theoretical reason why the conclusions reached should not be extended to any load mode present in the rock particles. Keeping this in mind, subscript $L$ will be omitted in the following.

In spite of the LEFM propagation criteria, it was observed that cracks may also grow in situations in which $K$ is lower than the fracture toughness. This is called subcritical crack growth, and it may be caused by several different mechanisms. The most familiar of these mechanisms is the fatigue due to repeated load application, but subcritical crack propagation may also be due to water-induced corrosion.

The theory of stress corrosion (Michalske \& Freiman, 1982; Atkinson \& Meredith, 1987) states that the strained inter-atomic bonds at the tip of a crack are more vulnerable to the attack of a corrosive agent, such as water, than the unstressed material away from the tip. The corrosion reaction produces a weaker material, which is broken at lower $K$ values than the uncorroded material. A typical relationship between crack propagation velocity, $V$, and $K$, as obtained from experiments performed in a constant relative humidity (RH) environment, is shown in Fig. 2 in qualitative terms. The thermodynamic formulation of the reaction rate theory (Laidler, 1987) applied to stress corrosion cracking (Wiederhorn et al., 1980, 1982; Freiman, 1984) yields the following general expression for the crack propagation velocity with water as corrosive agent:

$$
V=V_{0}(\mathrm{RH}) \exp [(-E++b K) / R T]
$$

where RH is the relative humidity in the testing environment, $K$ is the stress intensity factor in the crack, $T$ is the absolute

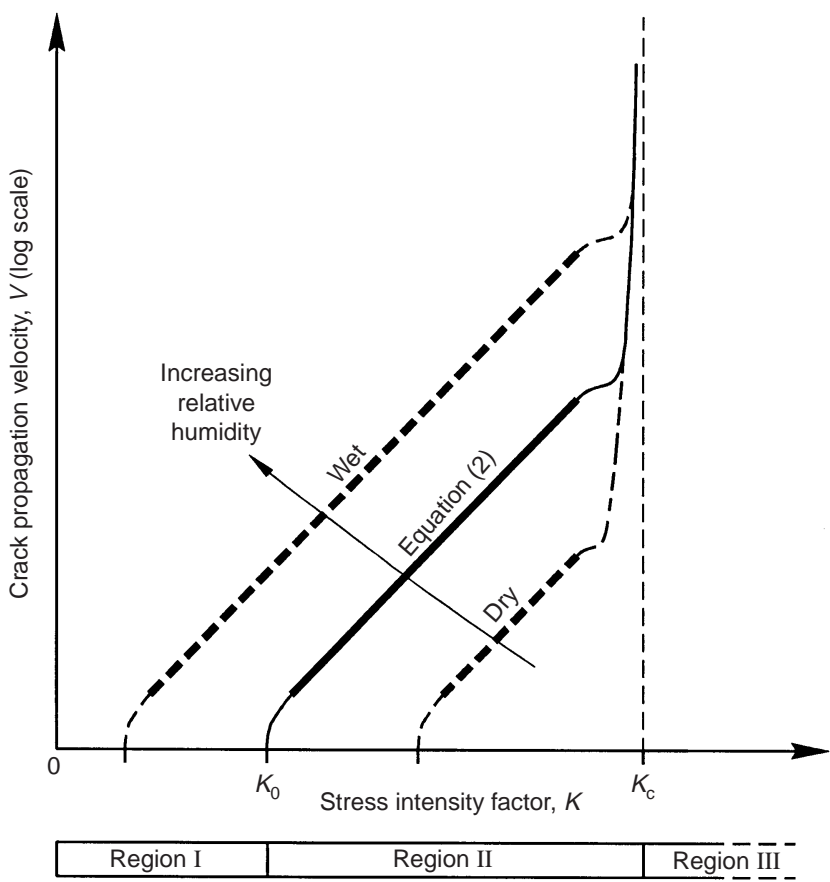

Fig. 2. Schematic subcritical crack growth curves and conceptual model of rockfill volumetric deformation 
temperature, $R$ is the gas constant, and $V_{0}, E \ddagger$ and $b$ are constants usually determined by fitting experimental data. This type of relationship, implied in the bold part of the curves in Fig. 2, holds for a large body of experimental data, mostly obtained for glasses and ceramics (Wiederhorn et al., 1980, 1982; Freiman, 1984), but also for rocks (Atkinson, 1984; Atkinson \& Meredith, 1987). Proportionality between $V$ and RH was found to hold for $\mathrm{RH}$ ranging from $20 \%$ to $100 \%$ in the case of soda lime-silica glass (Wiederhorn et al., 1982; Freiman, 1984). The use of RH in equation (2) is in fact a convenient way to measure the chemical potential of the corrosive agent-that is, water-which actually governs the rate of the corrosion reaction under constant $K$ (Wiederhorn et al., 1982).

Outside the region defined by the bold part of the curves in Fig. 2, different mechanisms, other than the reaction rate, control the crack propagation. A plateau in the relationship of $V$ to $K$ is observed in some materials for high $K$ values (Fig. 2). This is attributed to the fact that $V$ becomes controlled by the transport rate of the corrosive agent towards the crack tip and not by the reaction rate. Moreover, when $K$ approaches the fracture toughness $K_{\mathrm{c}}, V$ increases rapidly (catastrophic rupture) and becomes independent of relative humidity. On the other hand, it is usually assumed (although not yet experimentally confirmed for most rocks) that a stress corrosion limit, $K_{0}$, exists below which cracks do not propagate at all.

In the case where crack growth occurs in a liquid environment - that is, a solution of water and a non-aqueous solventit was observed that measured values of $V$ are proportional to the relative humidity of a gas in (thermodynamic) equilibrium with the solution (Freiman, 1984). Thermodynamic equilibrium implies that both gaseous environment and liquid environment will have equal chemical potentials, and hence they would produce the same effect on the stress corrosion reaction: that is, equal reaction rates and equal $V$ (Wiederhorn et al., 1982). This means that it does not matter whether the corrosive agent (water) is in the liquid or the gaseous state. Therefore the sole parameter that controls the influence of the corrosive agent on $V$ is the RH measured in the environment surrounding the specimen, provided that thermodynamic equilibrium is ensured.

Let us assume that we are able to compute the stress intensity factor $K$ for every crack or flaw existing in the rock particles of a rockfill sample. $K$ values will depend on the geometry of the particles, the crack lengths, and the load configuration. Then each crack within the rockfill sample would occupy a defined position along the $K$ axis of Fig. 2. Cracks lying in region I $\left(K \leqslant K_{0}\right)$ will not grow at all. Cracks lying in region II ( $K_{0}<K<K_{\mathrm{c}}$ ) will grow at a velocity controlled by load and by relative humidity. This crack growth implies in turn an increase in $K$ for most crack configurations, since it usually increases with the increase in crack length (see equation (1), although $K$ may also decrease with the increase of crack length for 'negative geometries'; Bazant \& Planas, 1998). Eventually, when $K$ values approach region III $\left(K \geqslant K_{\mathrm{c}}\right)$ an instantaneous particle breakage will occur. The associated rearrangement of the granular structure will lead to a macroscopic strain increment and a more stable configuration of contacts and contact loads.

By means of this mechanism, a conceptual explanation of the rockfill behaviour can be given. In a steady situation, all cracks will lie in region I and hence the rockfill does not deform. If a load increment is then applied, some cracks will move to region III, producing an instantaneous deformation increment. Some other cracks will fall in region II and cause the time-dependent component of deformation. Under constant load, the number of source cracks lying in region II will decrease in time owing to the breakage process, and this implies a reduction of strain rate with time. If relative humidity increases at a given time, cracks in region II will increase their propagation velocity, causing a sudden increase in the strain rate. Additionally, some cracks previously lying in region I will move to region II owing to the decrease in $K_{0}$ implied in Fig. 2, causing an additional amount of strain. This is, indeed, the nature of collapse: an increment of rockfill strain not related to an increment in load.

\section{ROCKFILL DEFORMATION TESTS}

The tested material is a slate obtained from the Pancrudo River outcrop (Aragón, Spain). The slate belongs to the Almunia formation, which has a Cambric origin. Its mineralogical composition, obtained from X-ray diffraction tests, includes quartz, muscovite, clinochlore, calcite and dolomite. The outcrop is planned to serve as quarry for the construction of the shells for the Jiloca River Regulation Dam, a zoned earth and rockfill dam. The engineering properties of the rock are summarized in Table 1 .

The water retention curve for rock-that is, the Pancrudo slate-is shown in Fig. 3. The retention curve characterizes the water storage features of the rock, and should serve as a reference material property when interpreting the collapse tests with suction control. For the range of water content values covered in this retention curve, water is essentially stored within the rock particles: that is, in the rock pores. As suction approaches zero, rock pores tend to become saturated. However, such a limiting condition is difficult to achieve in the retention curve experiments, although it can be defined by extending to very low suctions the interpolated retention curves shown. It is worth noting that the theoretical saturation water content of rock particles, computed from the rock porosity value given in Table 1 , is $3 \cdot 15 \%$, which is close to the limiting water content for zero suction derived from Fig. 3. The figure shows the results of several tests (equilibrium points connected by broken lines). For high suctions, a rock sample was stored in an

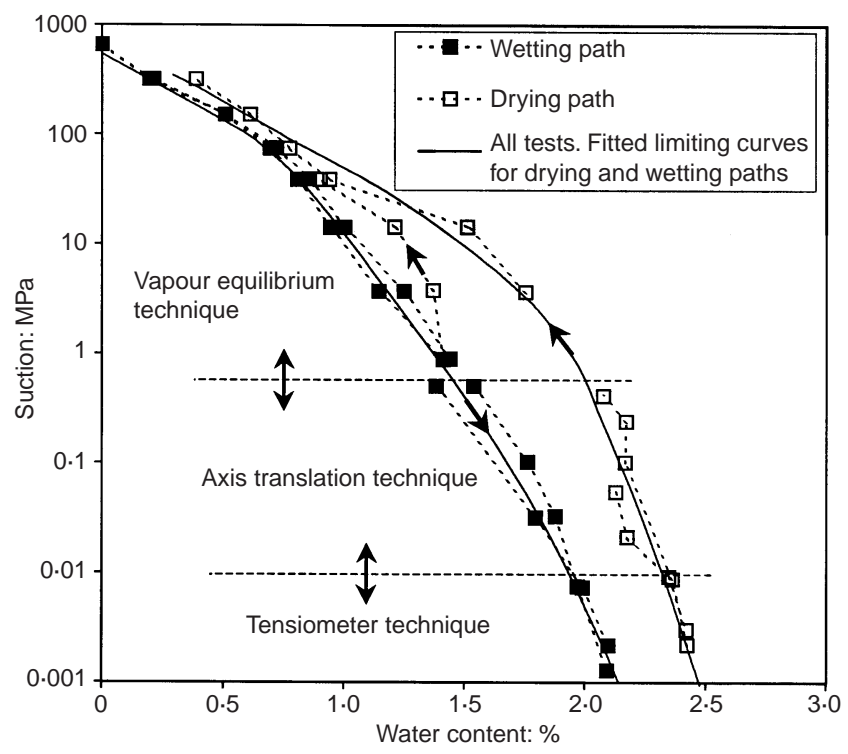

Fig. 3. Retention curve for the Pancrudo slate rock

Table 1. Properties of Pancrudo slate

\begin{tabular}{l|c|c}
\hline & Mean value & Range \\
\hline Uniaxial compression strength & $20 \cdot 5 \mathrm{MPa}$ & $14 \cdot 2-31 \cdot 9 \mathrm{MPa}$ \\
Solid specific gravity (ASTM C97-90) & $2 \cdot 754$ & - \\
Water absorption (ASTM C97-90) & $1 \cdot 356 \%$ & - \\
Porosity (from 84 mm core specimens) & $8 \%$ & $6 \cdot 3-11 \cdot 8 \%$ \\
\hline
\end{tabular}


isolated container where the RH was controlled by means of saturated saline solutions ('vapour equilibrium technique' in the figure). In the low-suction range, a ceramic suction plate was used to apply initially a negative water pressure to the rock pores ('tensiometer technique') and later an air overpressure ('axis translation technique') to the rock sample. A drying curve and a wetting curve (solid lines in Fig. 3) were fitted to all the experimental data.

A sample of crushed rock was obtained from the quarry with the aid of a digger. Recovered blocks having 200-400 mm maximum dimensions were broken down with the aid of a hammer. The maximum particle size for tests was fixed at $40 \mathrm{~mm}$, and the adopted grain size curve is shown in Fig. 4.

An oedometer test program, including five tests, was carried out in a Rowe-type cell, $300 \mathrm{~mm}$ sample diameter and an approximate sample height of $200 \mathrm{~mm}$. Specimen compaction was carried out directly in the oedometer ring by means of a handy compaction hammer specified for the Marshall test. This hammer delivers the same energy per blow as the modified Proctor hammer, but the compaction effort is transmitted to the material by means of a fixed base. This base prevents the hammer from striking the rock particles directly, thus preventing the grain breakage that would otherwise occur in the surface of each compaction layer. Specimens were compacted in four layers with a compaction energy in the range 600-700 J/1, which is close to the compaction energy used in the Standard Proctor Test $(584 \cdot 3 \mathrm{~J} / 1)$. All specimens tested reached a void ratio $e=0.55 \pm 0.03$ after compaction. All specimens were allowed to reach thermodynamic equilibrium with the laboratory environment (approximately $50 \% \mathrm{RH}$ and $22^{\circ} \mathrm{C}$ ), resulting in a low initial water content (under 1\%).

\section{Test procedure}

The test programme included three classic oedometer tests with specimen flooding at some particular confining stress (tests 1,2 and 3) and two oedometer tests with relative humidity control (tests 4 and 5). For tests 4 and 5 a relative humidity control system was added to the oedometer. The aim of this system is to produce a gradual variation in the specimen water content by adding controlled quantities of water in a uniform manner across the specimen. In order to achieve this goal, water has to be transported in vapour state. The system includes a closed-loop air circulation circuit, as shown schematically in Fig. 5. The air, impelled by an electric pump, bubbles in a solution vessel and then flows across the specimen from the upper to the lower drainage plate. Saline solutions were used in

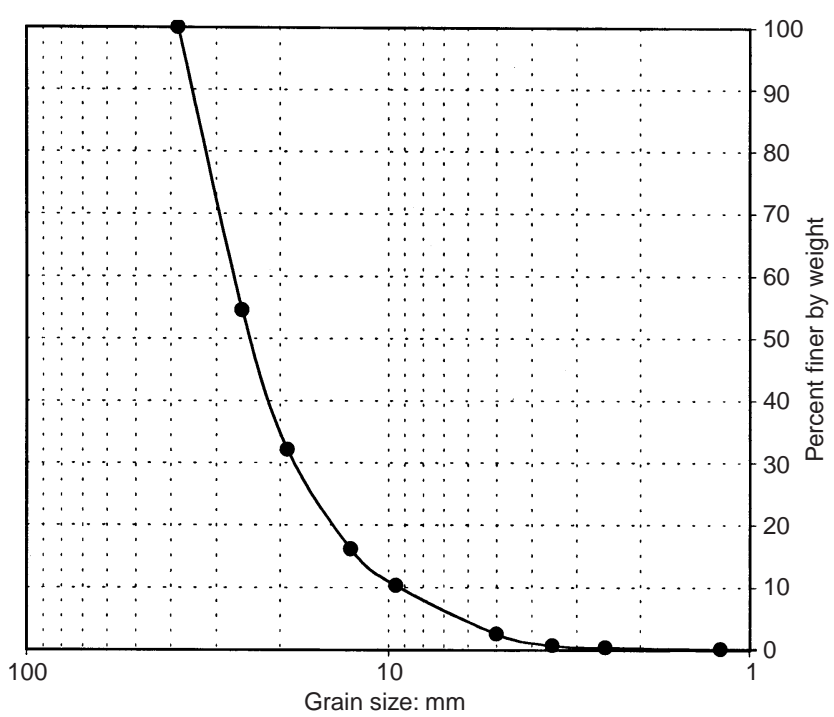

Fig. 4. Grain size distribution of the tested material

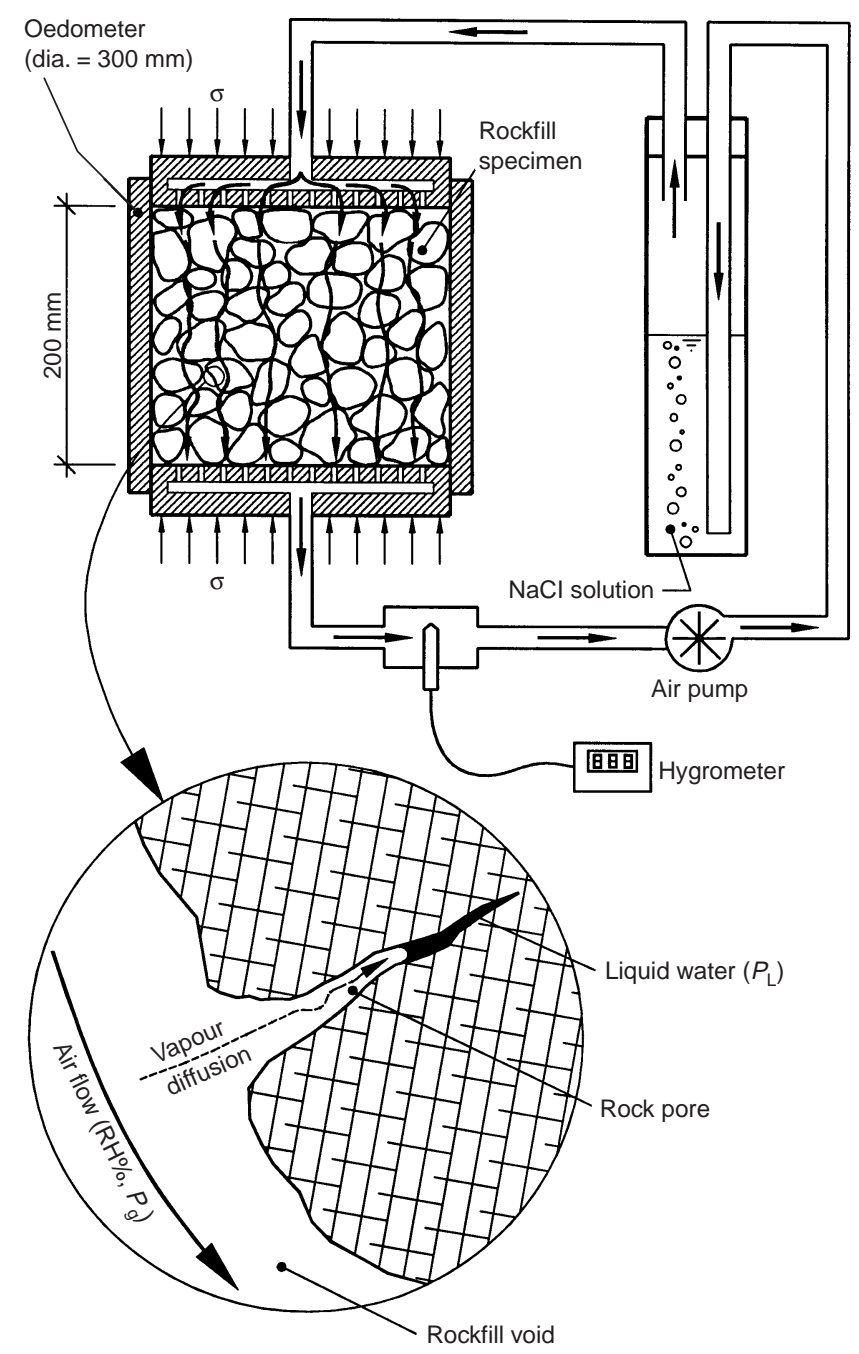

Fig. 5. Rockfill oedometer test set-up with a relative humidity control system

order to impose a controlled relative humidity to the air flow. A hygrometer inserted in the air flow coming out of the specimen allowed the progress of the test to be monitored.

As the test proceeds, the air flows through the rockfill voids, impelled by the pump. In a wetting path, the RH imposed by the solution in the air flow is larger than the current $\mathrm{RH}$ within the rock pores. Water vapour is transported from the vessel to the rockfill voids by advection. Further transport of water vapour occurs from rockfill voids to rock pores by molecular diffusion owing to the $\mathrm{RH}$ gradient created between rockfill voids and rock pores. Water vapour will condense within the rock pores wherever the width of the pore is smaller than approximately twice the radius of curvature at equilibrium of the gas-liquid interface (see detail in Fig. 5). The curvature depends on the surface tension of water and the difference between the gas pressure and the pressure in liquid water. This difference is usually termed the matric suction, $s=p_{\mathrm{g}}-p_{1}$.

The absorption of water by the rockfill specimen during the test was measured by recording the loss of weight of the solution vessel. Under constant imposed RH, the rate of water absorption decreased gradually until an equilibrium state (nil absorption rate) was reached. When the whole system (specimen and RH control device) reaches thermodynamic equilibrium, the $\mathrm{RH}$ is equal at any point of the system's gas phase, and no further transport of water vapour can occur. In such an equilibrium state, the RH in the gas phase and the matric suction in the rock pore water are related by the psychrometric relationship (Coussy, 1995): 


$$
\mathrm{RH}=\exp \left[-\frac{v(s+\pi)}{R T}\right]
$$

where $v$ is the molar volume of liquid water and $\pi$ is called the osmotic suction, which is due to the presence of solutes in the rock pore water. The sum $\psi=s+\pi$ is usually called the total suction. Total and matric suction would be equal in the case where rock pores contained only pure water with no solutes.

\section{Test results}

Figure 6 shows plots of vertical strain against vertical stress in $\log$ and natural scales for the five oedometer tests carried out. The load was applied in increments, allowing the sample to deform for a maximum of $24 \mathrm{~h}$ before the application of the next load increment. The stress-strain curves in Fig. 6 correspond to a constant time interval of $1000 \mathrm{~min}$. Fig. 7 shows the paths followed by the four tests in the vertical stress-total suction space. Total suction, derived from the RH measurements using equation (3), has here the physical meaning given in the previous section: it is the sum of matric suction plus osmotic suction existing in the liquid water contained in the rock pores, and it is assumed to be in thermodynamic equilibrium with the specimen's gas phase (that is, the air filling the rockfill voids). On the other hand, it seems reasonable to assume that, in a rockfill, suction does not introduce relevant inter-particle capillary forces, as is the case for soils.

It is worth noting that if stresses are represented in a natural scale, the normal compression lines corresponding to the 'dry' stage (initial water content) of tests 2, 3 and 4 (Fig. 6(b)) plot nearly as straight lines passing through the origin. Fig. 8 shows unloading-reloading compression curves for the dry stage of tests 2 and 3 (which were omitted in the previous figures for simplicity). It is apparent that permanent deformations occur from the very beginning of the test (under very low stresses), suggesting that rockfill has no initial elastic region during first loading.

In test 1 , the specimen was flooded at a very low load $(0.01 \mathrm{MPa})$. During flooding, and for an additional period of $24 \mathrm{~h}$, a moderate swelling of specimen 1 was recorded (Fig. 6(b)). The total measured swell was $0 \cdot 27 \%$. Under further load increase, the normal compression for this saturated specimen also approaches a straight line but only beyond a threshold stress (close to $0.4 \mathrm{MPa}$ ), and shows a softer behaviour than the dry specimens.

Collapse due to specimen flooding was observed in test 3 under $0.6 \mathrm{MPa}$ constant vertical stress. The amount of collapse strain was very close to the strain difference between the normal compression lines corresponding to the initial water content (dry state) and the saturated state. The subsequent loading after collapse leads to a stress-strain curve that follows the NCL for the saturated material obtained in tests 1 and 2 . Fig. 9 shows a photograph of specimen 3 after test completion.

The behaviour of specimen 2 during flooding contrasts with the collapse observed in test 3 . It was flooded after reaching a vertical stress of $1 \mathrm{MPa}$, unloading to $0.03 \mathrm{MPa}$ and reloading up to $0.2 \mathrm{MPa}$ (Figs 6(b) and 7). No collapse was observed

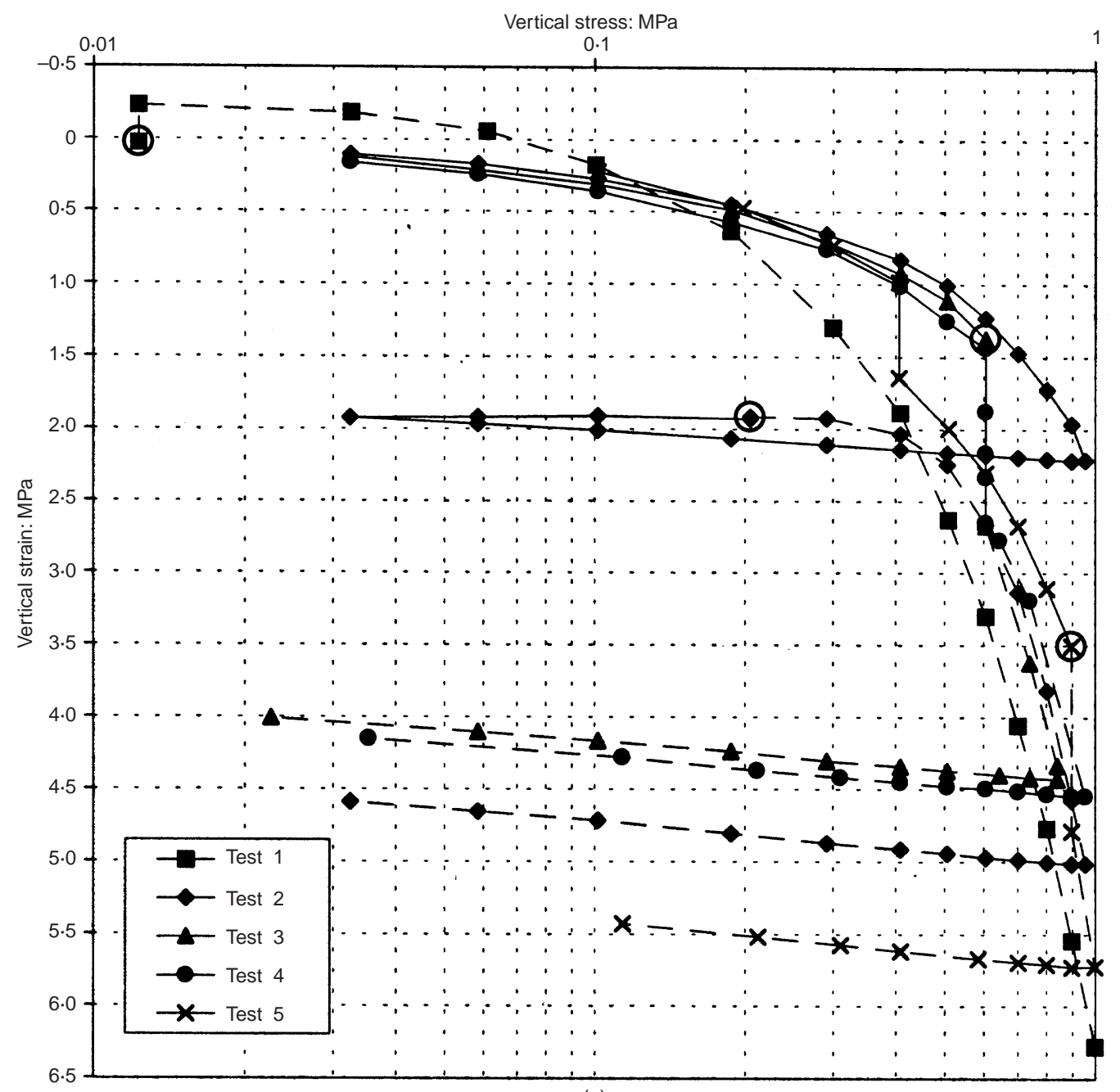

(a)

Fig. 6. Results of one-dimensional compression test on rockfill: (a) vertical stress in logarithmic scale; (b) (overleaf) vertical stress in natural scale. Broken lines indicate the saturated condition of rock pores (either by specimen flooding or by RH increase). Open circles indicate specimen flooding 


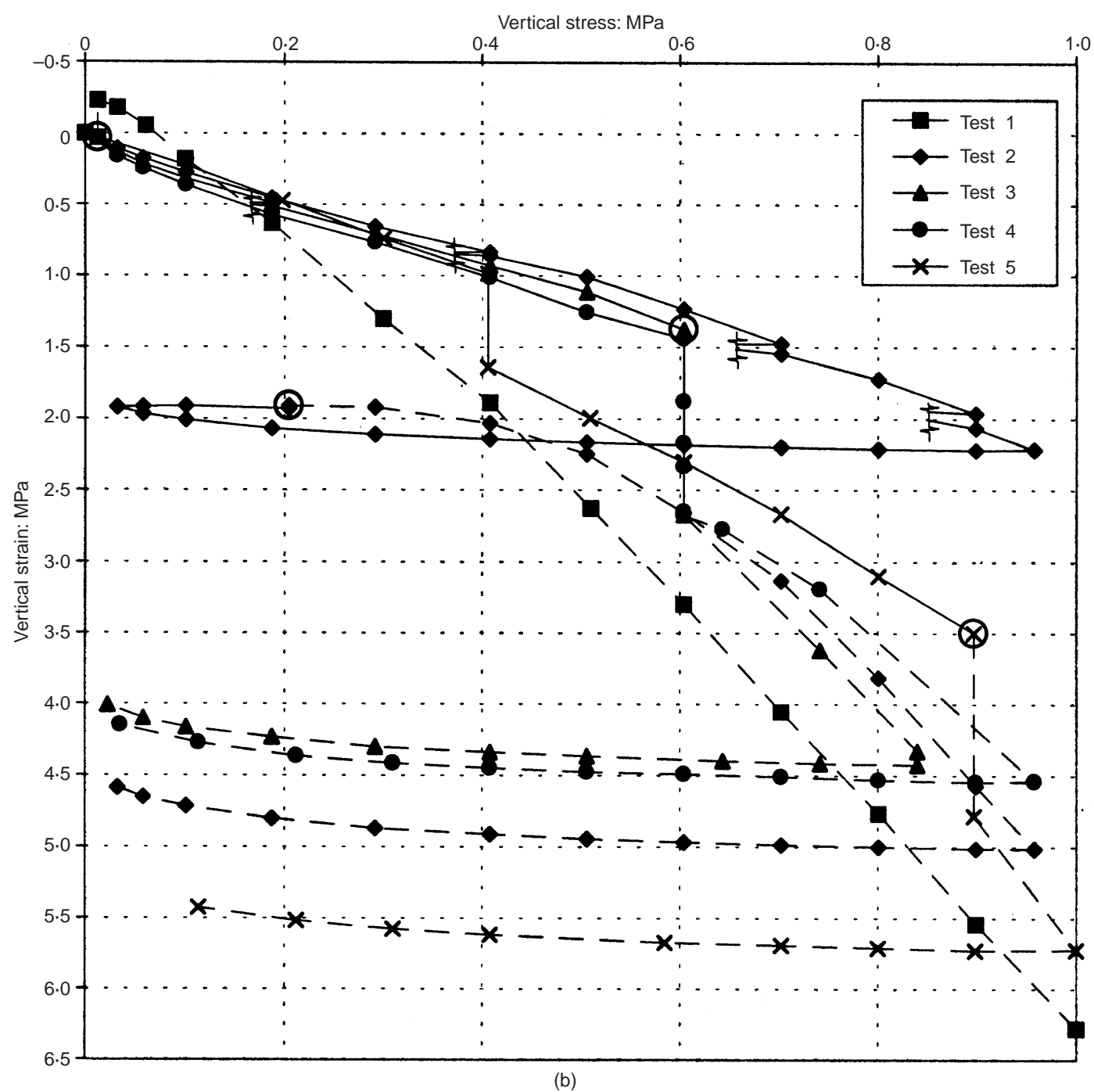

Fig. 6. (continued)

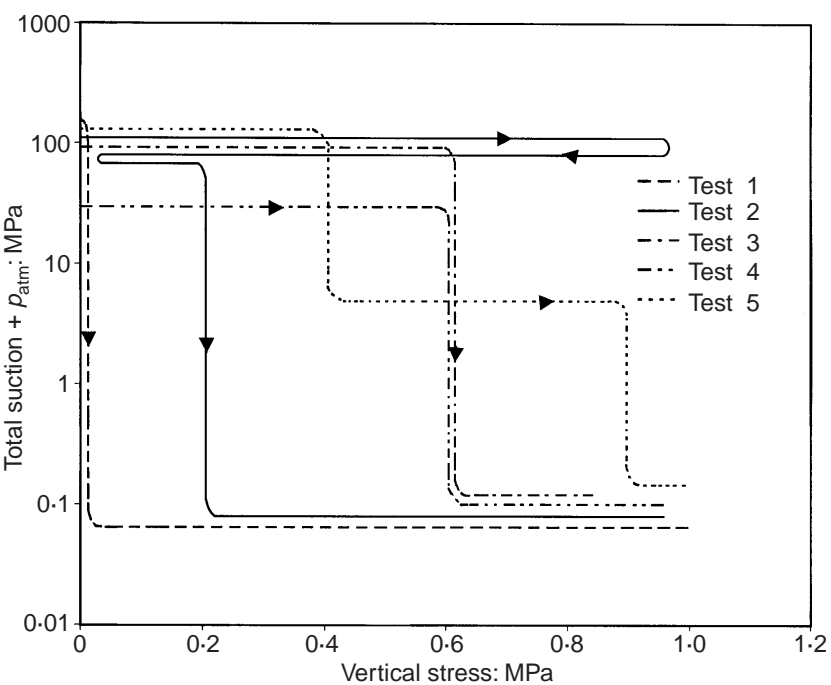

Fig. 7. Vertical stress-total suction paths followed by tests

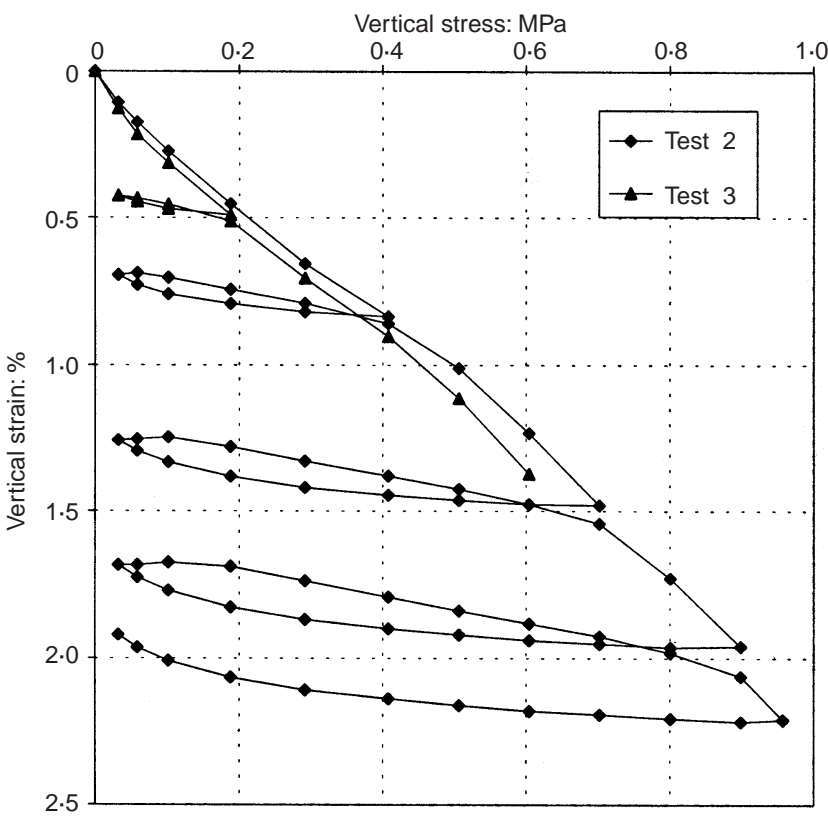

Fig. 8. NCL and URL for 'very dry' rockfill. Vertical stress in natural scale 


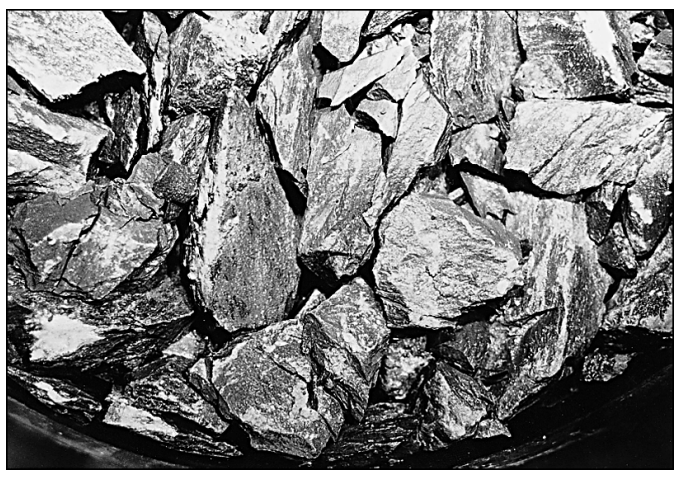

Fig. 9. Photograph of specimen 3 after test completion

during saturation. Instead, a small swelling $(0.016 \%$ axial strain) was measured. Once saturated, the strain-stress curve under a new load increase approaches the NCL for the saturated material obtained in test 1 .

Test 4 has a stress path identical to that of test 3 , but during the collapse process the relative humidity was controlled by means of the previously described set-up. The aim of this test was to induce collapse in a gradual manner as water content increases. Figs 10 and 11 show plots of collapse strain against water content and collapse strain against total suction for the data recorded during test 4 . Note that specimen 4 was never flooded, and the 'bulk degree of saturation' (referred to the saturation of both rock pores and rockfill voids) remained quite low during the whole test. As can be seen in Fig. 10, the final water content of specimen 4 at the end of collapse was $3 \cdot 2 \%$. By contrast, sample 3 was fully saturated during flooding, and it reached a water content of nearly $20 \%$. Nevertheless, the amount of collapse strain that occurred in both specimens is almost the same.

Test 5 was carried out at a later date with the objective of serving as a verification test for the constitutive model developed. It followed the stress-total suction path shown in Fig. 7. The specimen response will later be compared with model predictions.

\section{Discussion and interpretation}

On the basis of the reported tests, it may be accepted that a unique normal compression line exists for a given total suction or water content. The stiffness during normal compression depends on suction: the material stiffens as total suction increases. An elastic domain may also be defined if small hysteresis effects are neglected. The effect of wetting (decreasing suction) depends on the applied confining stress. For low stress levels (small) swelling strains are measured, whereas collapse strains occur beyond a certain confining stress value. This is also a feature implied in the previously presented rockfill conceptual model (Fig. 2). In fact, if rockfill is wetted under low stress (low $K$ value), the material will not deform at all (no collapse). However, if stress is increased, $K$ values will move towards region II and the associated cracks will react with a rapid increase in their propagation velocity if an increase in relative humidity occurs.

Test 4 , in which collapse was produced by gradually raising the relative humidity, showed that the water content at the end of the wetting path was a small fraction $(\sim 15 \%)$ of the saturation water content of the rockfill (given by the water weight necessary to fill both rock pores and rockfill voids). If the specimen water content at the end of the wetting path $(w=3.2 \%$, see Fig. 10) is referred to the water retention curve of the rock (Fig. 3), it appears that during test 4 the major part of the liquid water was essentially stored within the rock particles (that is, in the rock pores), and that only a very small amount of liquid water was present in the rockfill voids. This fact was confirmed by visual inspection at the end of test 4 . Hence saturation of the rock particles seems sufficient to

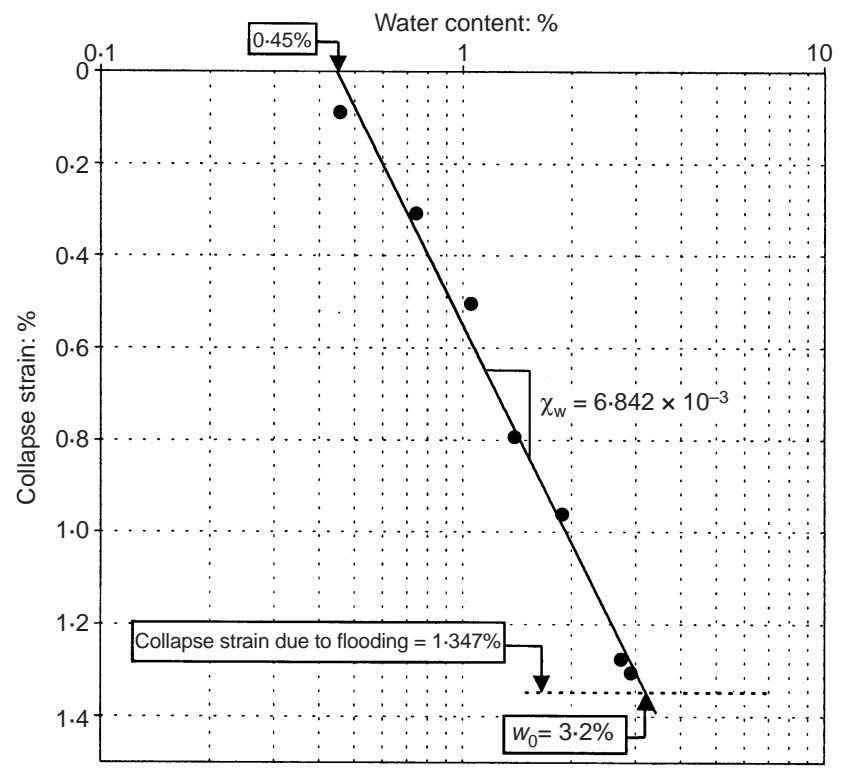

Fig. 10. Collapse strain plotted against gravimetric water content in oedometer test 4 . Vertical stress $=0 \cdot 6 \mathrm{MPa}$

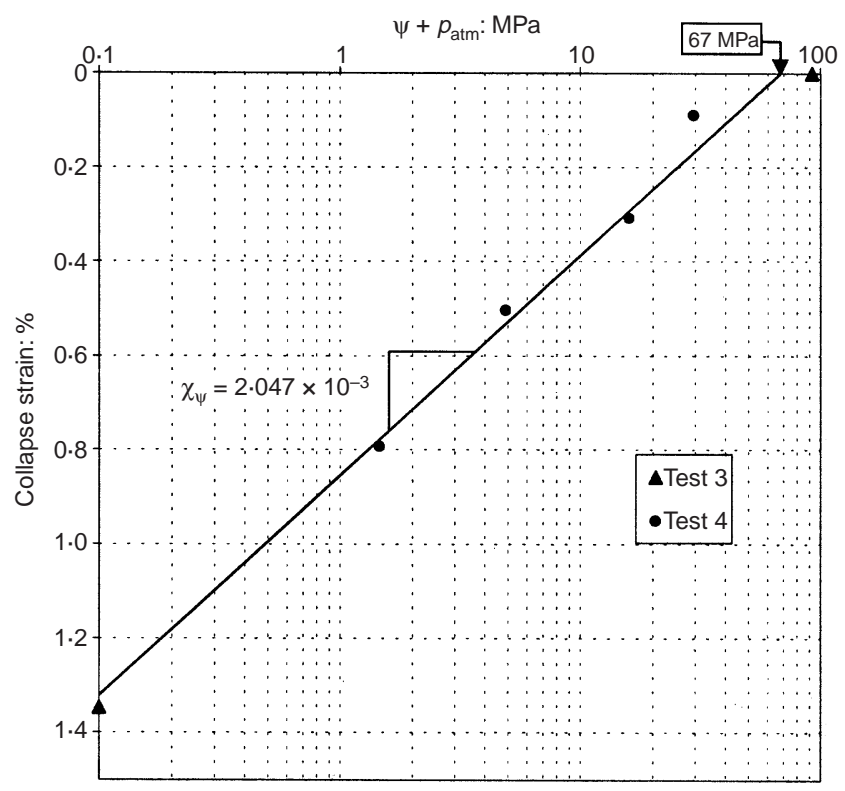

Fig. 11. Collapse strain plotted against total suction under 0.6 MPa vertical stress (tests 3 and 4 )

produce the same collapse deformation as a full flooding of the rockfill specimen.

An additional analysis of the observed behaviour was carried out by distinguishing the instantaneous strain increments caused by each load increment from the subsequent time-dependent strains in tests $1-4$. The incremental instantaneous compliance and the incremental time-dependent compliance are plotted in Figs 12(a) and 12(b) against the applied stress. Incremental compliance is defined as the strain increment, either instantaneous or time dependent (a time period of 1000 minutes was considered), divided by the stress increment. Instantaneous strains are the major component of strain for low confining stresses: they tend to decrease when confining stress increases, and they are only slightly affected by sample flooding. On the other hand, time-dependent strains are relatively low for low confining stresses and dry states. Beyond a certain threshold stress value the time-dependent strains are strongly affected by water: that is, the time-dependent compliance rapidly increases with increasing water content. Unlike conventional granular soil behaviour, the rockfill time-dependent strain component is not 


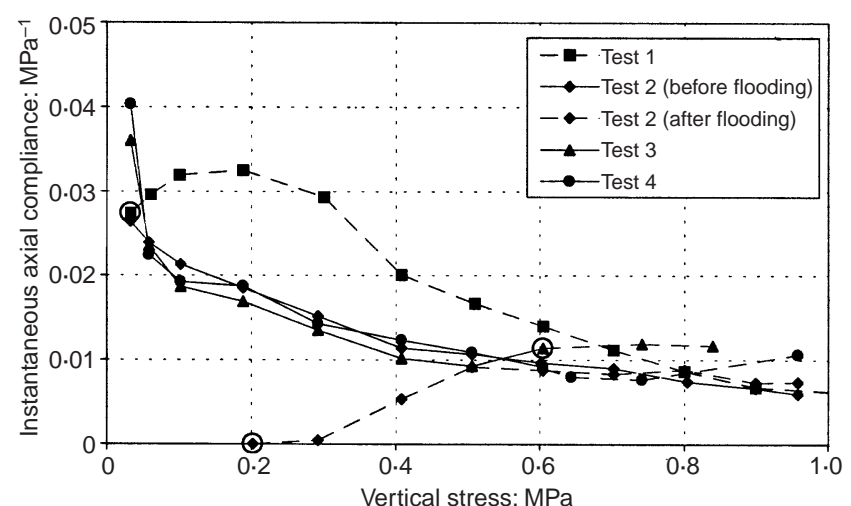

(a)

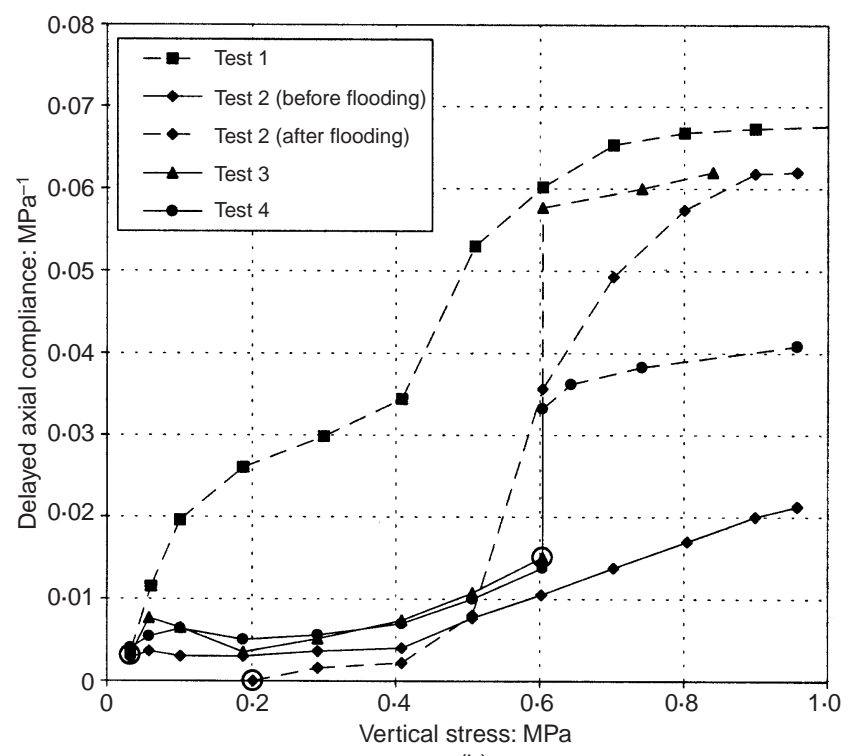

(b)

Fig. 12. Axial compliance computed from: (a) the instantaneous strain increments; (b) the time-deferred strain increments. Broken lines indicate the saturated condition of rock pores (either by specimen flooding or by RH increase). Open circles indicate specimen flooding

negligible, as Fig.12(b) demonstrates. Furthermore, these timedependent deformations incorporate the effect of water and explain the rockfill collapse behaviour. These features will be taken into account to formulate a constitutive model for rockfill compressibility.

\section{COMPRESSION MODEL FOR ROCKFILL}

McDowell \& Bolton (1998) distinguish four successive deformation mechanisms of granular materials in compression as the confining stress is increased. Under low stresses, deformation is due to particle rearrangement. The second mechanism is called clastic yielding, and it is attained when the applied stress causes the onset of particle crushing. This stage is marked by a strongly curved strain-log stress relationship, with concavity directed towards the strain axis. However, when plotted in natural scale the particle rearrangement and clastic yielding stages appear as a nearly linear strain-stress relationship for many previously published experimental data for granular materials (Nobari \& Duncan, 1972; Marsal, 1973; Clements, 1981; Pestana \& Whittle, 1995; Yamamuro et al., 1996). If load is further increased, particle crushing continues and a granular structure arises in which the grain size distribution is a fractal and neighbouring particles are never of equal size (Sammis, 1997). McDowell \& Bolton (1998) showed that, in such a granular structure, only the smallest particles would undergo crushing under the successive stress increments. Successive reduction of the smallest particle size is called clastic hardening and it was shown that the strain-log stress relationship during this stage should be linear, as observed in many experimental results. Finally, for very high stresses the strain-log stress relationship has an upward-directed concavity. This is attributed to the comminution limit of small particles (McDowell \& Bolton, 1998).

Deformations due to particle rearrangement under the first load increments can be identified in the strain-stress curves shown in Fig. 8 (upward concavity) for stresses varying from 0 to $0.4 \mathrm{MPa}$ approximately. Clastic yielding seems to occur beyond this threshold value, and it leads to a nearly linear strain-stress relationship. Neither the clastic hardening mechanism nor the comminution limit are attained within the stress range used in the test programme.

This interpretation, which is based on the shape of the strain-stress curves, is also consistent with the proposed conceptual model and the analysis of instantaneous and timedependent strains discussed before. In fact, clastic yielding initiates beyond a threshold stress value since it is associated with crack propagation, which requires a minimum stress intensity factor $K_{0}$ to develop (Fig. 2). Since time-dependent deformations are associated with crack propagation it also follows from Fig. 2 that for a very dry state (low vapour pressure) time-dependent strains vanish since $K_{0}$ tends to $K_{\mathrm{c}}$ and the region II disappears. For a wet state of the material, both instantaneous and time-dependent strains should occur within the clastic yielding stage.

Two deformation mechanisms producing plastic strains are included in the proposed model: the instantaneous deformation mechanism (IDM) and the time-dependent deformation mechanism (TDM). However, no time dependence is explicitly taken into account by the model presented here.

In view of Fig. 12(a) it will be assumed that the IDM is present at any stress level and stress increment. It is considered independent of water action. On the other hand, the TDM is active beyond a threshold total stress value, $\sigma_{\mathrm{y}}$, and depends strongly on the water action. It is the source of the collapse phenomenon, and vanishes when the material is in 'very dry state'. A more precise definition of such a 'very dry state' will arise from the model formulation.

The effect of water will be introduced in two alternative ways: either as the gravimetric water content, $w$, or by means of the total suction, $\psi$. Suction is used here as a parameter and not as a true stress variable. Both formulations (water content and suction based) are similar, and if the uniqueness of the retention curve is assumed, they are completely equivalent.

Linear normal compression lines are assumed for both IDM and TDM, and also a linear strain-stress relationship is assumed for unloading-reloading paths. The incremental strainstress relationship along the normal compression line results from the addition of the strains increments produced by both mechanisms:

$$
\begin{array}{ll}
\text { for } \sigma \leqslant \sigma_{\mathrm{y}} & \mathrm{d} \varepsilon=\mathrm{d} \varepsilon^{\mathrm{i}}=\lambda^{\mathrm{i}} \mathrm{d} \sigma \\
\text { for } \sigma>\sigma_{\mathrm{y}} & \mathrm{d} \varepsilon=\mathrm{d} \varepsilon^{\mathrm{i}}+\mathrm{d} \varepsilon^{\mathrm{d}}=\left[\lambda^{\mathrm{i}}+\lambda^{\mathrm{d}}(w)\right] \mathrm{d} \sigma \\
\text { or } & \mathrm{d} \varepsilon=\mathrm{d} \varepsilon^{\mathrm{i}}+\mathrm{d} \varepsilon^{\mathrm{d}}=\left[\lambda^{\mathrm{i}}+\lambda^{\mathrm{d}}(\psi)\right] \mathrm{d} \sigma
\end{array}
$$

where $\sigma$ is the vertical stress applied in the oedometer, $\sigma_{\mathrm{y}}$ is the clastic yield stress (that is, the stress threshold value that marks the onset of particle breakage), $\varepsilon$ is the total vertical strain, $\varepsilon^{\mathrm{i}}$ and $\varepsilon^{\mathrm{d}}$ are respectively the IDM strain component and the TDM strain component, $\lambda^{\mathrm{i}}$ is the slope of the normal compression line when only the IDM is active, and $\left(\lambda^{\mathrm{i}}+\lambda^{\mathrm{d}}\right)$ is the slope of the normal compression line when both plastic deformation mechanisms are active.

Overall rockfill water content may be split in two parts: the significant water content (which varies from zero to the saturation water content of rock particles, $w_{0}$ ) and the dead water content that will fill the rockfill voids and will have no effect on the collapse behaviour. Suction, $\psi$, is related (through the retention curve) to the significant water content. 
The elastic strain increments within unloading-reloading (URL) paths are given by

$$
\mathrm{d} \varepsilon^{\mathrm{e}}=\kappa \mathrm{d} \sigma
$$

where the slope $\kappa$ is assumed to be independent of the water action. The observed moderate swelling behaviour caused by the increase in water content is assumed to be a reversible (elastic) strain. A linear relationship is assumed to exist between the swelling strain and the logarithm of water content, $w$ :

$$
\mathrm{d} \varepsilon^{w}=-\kappa_{w} \frac{\mathrm{d} w}{w}
$$

or $\psi$,

$$
\mathrm{d} \varepsilon^{\psi}=\kappa_{\psi} \frac{\mathrm{d} \psi}{\left(\psi+p_{\text {atm }}\right)}
$$

where $p_{\text {atm }}$ is the atmospheric pressure and $\kappa_{\mathrm{w}}$ and $\kappa_{\psi}$ are the water content and suction based expansion/compression indexes. For simplicity, $\kappa_{\mathrm{w}}$ and $\kappa_{\psi}$ are assumed to be independent of the stress level.

Yield surface, hardening law and flow rule for the water content formulation

Consider in Fig. 13(b) the behaviour of two identical rockfill samples that are initially in a very dry state (water content $w_{\mathrm{i}}$ close to zero; point $\mathrm{O}$ ). Water is added to one of them in an

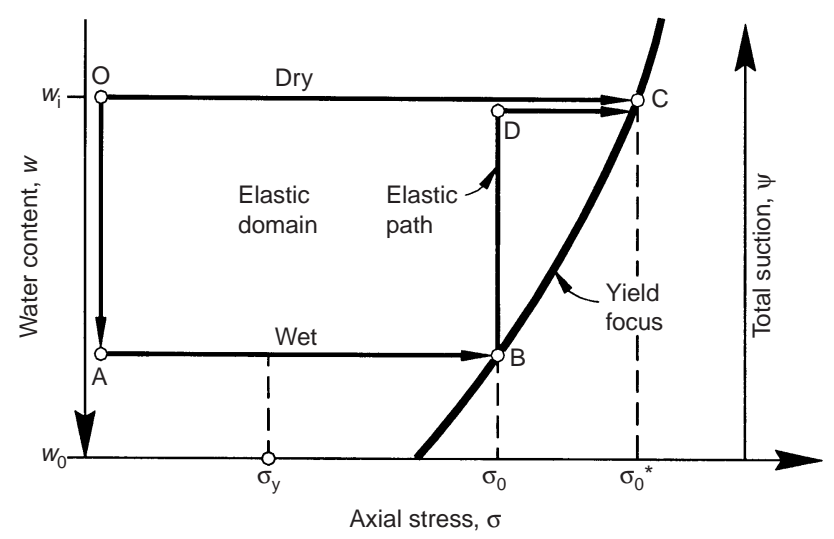

(a)

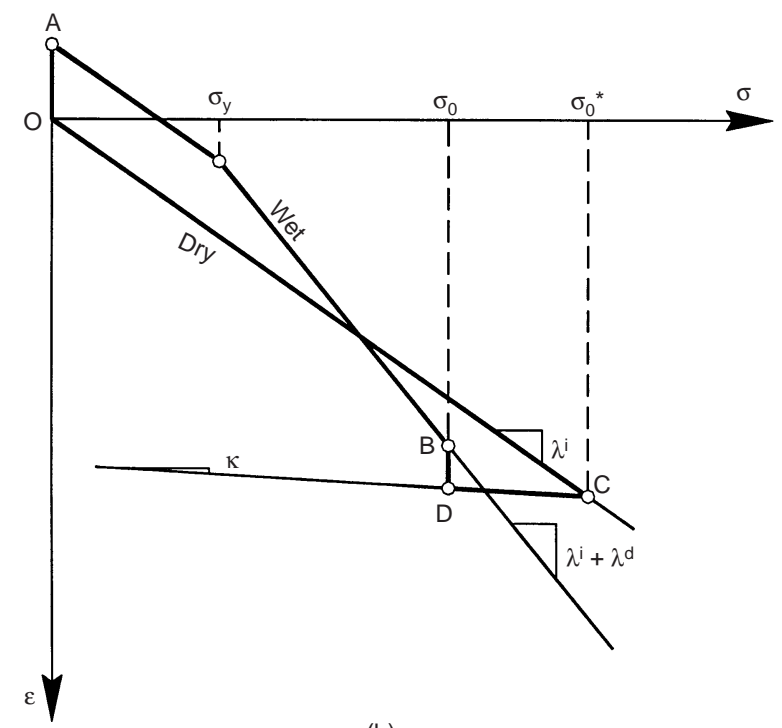

(b)

Fig. 13. (a) Stress paths considered to derive the yield surface. (b) Idealized model response unstressed state until a water content $w$, smaller than the rock saturation water content, is reached $\left(w<w_{0}\right)$. As observed in the experiments, the increase in water content will cause a moderate swelling up to point A. The 'wet' sample is then loaded up to a vertical stress $\sigma_{0}$ larger than $\sigma_{\mathrm{y}}$ (point B). The 'dry' sample is loaded up to a stress $\sigma_{0}^{*}$ larger than $\sigma_{0}$ (point C). If the 'stress states' $\mathrm{B}$ and $\mathrm{C}$ belong to the same yield surface, then it should be possible to carry the 'wet' sample from state $\mathrm{B}$ to state $\mathrm{C}$ by means of a virtual elastic path (Fig. 13(a)). This involves a constant stress drying from $B$ to $D$ and a constant water content loading from $\mathrm{D}$ to $\mathrm{C}$. The following equation expresses the deformation at point $\mathrm{C}$ computed along two alternative paths $\mathrm{OABDC}$ and $\mathrm{OC}$ :

$$
\begin{aligned}
-\kappa_{\mathrm{w}} \ln \left(w / w_{\mathrm{i}}\right)+\lambda^{\mathrm{i}} \sigma_{\mathrm{y}} & +\left[\lambda^{\mathrm{i}}+\lambda^{\mathrm{d}}(w)\right]\left(\sigma_{0}-\sigma_{\mathrm{y}}\right) \\
& +\kappa_{\mathrm{w}} \ln \left(w / w_{\mathrm{i}}\right)+\kappa\left(\sigma_{0}^{*}-\sigma_{0}\right)=\lambda^{\mathrm{i}} \sigma_{0}^{*}
\end{aligned}
$$

Rearranging this expression, the yield surface in the $\sigma-w$ space is derived as

$$
F(\sigma, w)=\sigma_{0}\left[\lambda^{\mathrm{i}}+\lambda^{\mathrm{d}}(w)-\kappa\right]-\sigma_{\mathrm{y}} \lambda^{\mathrm{d}}(w)-\sigma_{0}^{*}\left(\lambda^{\mathrm{i}}-\kappa\right)=0
$$

where $\sigma_{0}^{*}$, the yield stress of the dry state rockfill, is appropriately selected as the hardening parameter. Equation (9a) is the yield surface for $\sigma>\sigma_{\mathrm{y}}$. If the stress state does not exceed the clastic yield stress, $\sigma_{\mathrm{y}}$, the yield surface simply reads

$$
F(\sigma, w)=\sigma_{0}-\sigma_{0}^{*}=0
$$

A simple plastic volumetric strain hardening law is proposed:

$$
\mathrm{d} \sigma_{0}^{*}=\frac{\mathrm{d} \varepsilon^{\mathrm{p}}}{\lambda^{\mathrm{i}}-\kappa}
$$

Applying the consistency condition, the flow rule becomes

$$
\text { for } \begin{aligned}
\sigma>\sigma_{\mathrm{y}}: \quad \mathrm{d} \varepsilon^{\mathrm{p}}= & {\left[\lambda^{\mathrm{i}}+\lambda^{\mathrm{d}}(w)-\kappa\right] \mathrm{d} \sigma_{0} } \\
& +\left(\sigma_{0}-\sigma_{\mathrm{y}}\right) \frac{\partial \lambda(w)}{\partial w} \mathrm{~d} w
\end{aligned}
$$

for $\sigma \leqslant \sigma_{\mathrm{y}}: \quad \mathrm{d} \varepsilon^{\mathrm{p}}=\left[\lambda^{\mathrm{i}}-\kappa\right] \mathrm{d} \sigma_{0}$

A linear relationship between collapse strains and the logarithm of rock water content was observed in the experiments carried out (Fig. 10). It is therefore suggested that the compressibility coefficient $\lambda^{\mathrm{d}}(w)$ accounting for clastic yielding is linearly related to the logarithm of water content through a material parameter $\alpha_{\mathrm{w}}$ :

$$
\lambda^{\mathrm{d}}(w)=\lambda_{0}^{\mathrm{d}}-\alpha_{\mathrm{w}} \ln \left(\frac{w_{0}}{w}\right)
$$

where $\lambda_{0}^{\mathrm{d}}$ is the maximum clastic compressibility index (for $\left.w \geqslant w_{0}\right)$. Therefore $\lambda^{\mathrm{d}}(w)$ is bounded as follows:

$$
0 \leqslant \lambda^{\mathrm{d}}(w) \leqslant \lambda_{0}^{\mathrm{d}}
$$

The lower bound condition in equation (13) allows the 'very dry state' to be defined. For the case of the Pancrudo slate tested in this work, this state is attained for $w \leqslant 0.45 \%$, as implied in Fig. 10.

A relationship between $\alpha_{\mathrm{w}}$ and the experimental coefficient $\chi_{\mathrm{w}}$ defined in Fig. 10 may be derived if the collapse strains measured in experiments are compared with predicted strain as given by the model. For an incremental wetting path at constant stress $\sigma_{0}\left(\sigma_{0}>\sigma_{\mathrm{y}}\right)$, the total strain increment is given by the sum of elastic and plastic components (equations 7(a) and 11(a) respectively):

$$
\mathrm{d} \varepsilon_{\text {collapse }}=-\kappa_{\mathrm{w}} \frac{\mathrm{d} w}{w}+\left(\sigma_{0}-\sigma_{\mathrm{y}}\right) \alpha_{\mathrm{w}} \frac{\mathrm{d} w}{w}
$$

The measured collapse strain increment will be given by (Fig. 10) 


$$
\mathrm{d} \varepsilon_{\text {collapse }}=\chi_{\mathrm{w}} \frac{\mathrm{d} w}{w}
$$

Therefore

$$
\alpha_{\mathrm{w}}=\frac{\kappa_{\mathrm{w}}+\chi_{\mathrm{w}}}{\sigma_{0}-\sigma_{\mathrm{y}}}
$$

Figure 14 shows the shape of the yield surface in a $(w, \sigma)$ space for different values of $\sigma_{0}^{*}$. Three regions that do not depend on water content may be identified. They correspond to stress levels below the clastic yield stress, $\sigma_{\mathrm{y}}\left(\sigma_{\mathrm{y}}=0.29 \mathrm{MPa}\right.$ for the Pancrudo slate), to very dry states $(w \leqslant 0.45 \%)$, and to water contents in excess of the rock particles' saturation water content, $w_{0}(w \geqslant 3 \cdot 20 \%)$, respectively. As concluded from experimental observations, within the two first regions the TDM is not activated, and deformations are due only to the IDM. Within the third region, the TDM is fully activated since rock particles are saturated.

\section{Total suction formulation}

Figure 12, which relates measured collapse strains and total suction, is now used in a similar way to relate the suction-based compressibility coefficient, $\lambda^{\mathrm{d}}(\psi)$, to changes in total suction:

$$
\lambda^{\mathrm{d}}(\psi)=\lambda_{0}^{\mathrm{d}}-\alpha_{\psi} \ln \left(\frac{\psi+p_{\mathrm{atm}}}{p_{\mathrm{atm}}}\right)
$$

where $\alpha_{\psi}=\left(\kappa_{\psi}+\chi_{\psi}\right) /\left(\sigma_{0}-\sigma_{\mathrm{y}}\right)$ and $\chi_{\psi}$ is defined in Fig. 11 .

As for the water content formulation, $\lambda^{\mathrm{d}}(\psi)$ should always be positive, and this condition yields the definition of the 'very dry state' in terms of total suction. For the Pancrudo slate $\psi \geqslant 67 \mathrm{MPa}$, which corresponds approximately to $61 \% \mathrm{RH}$ at $20^{\circ} \mathrm{C}$ (see Fig. 11)

By replacing $\lambda^{\mathrm{d}}(w)$ in equation 9(a) with the expression for $\lambda^{\mathrm{d}}(\psi)$ given in equation (17), the yield surface is obtained. A plot of the yield curves for different values of $\sigma_{0}^{*}$ is given in Fig. 15 for the Pancrudo slate. Also indicated in Fig. 15 are the two $(\sigma, \psi)$ regions in which the rockfill behaviour does not depend on total suction. They correspond to stress levels below the clastic yield stress $\sigma_{\mathrm{y}}(\sigma \leqslant 0.29 \mathrm{MPa})$ and to very dry states $(\psi \geqslant 67 \mathrm{MPa})$ respectively.

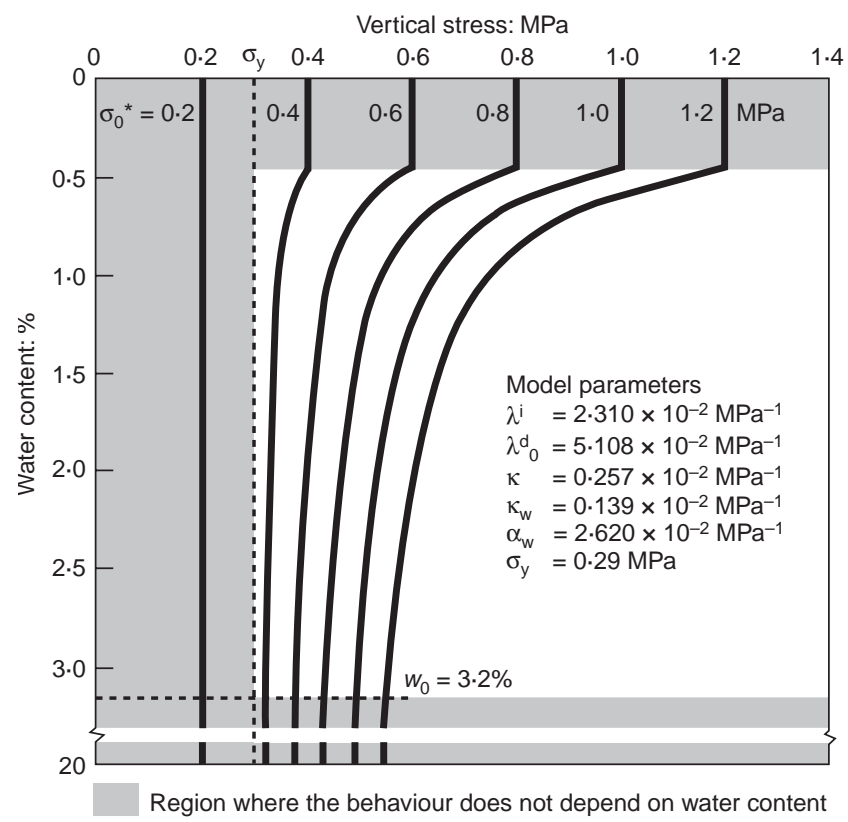

Fig. 14. Water content formulation. Yield surfaces for different values of the hardening parameter $\sigma_{0}^{*}$. Pancrudo rockfill

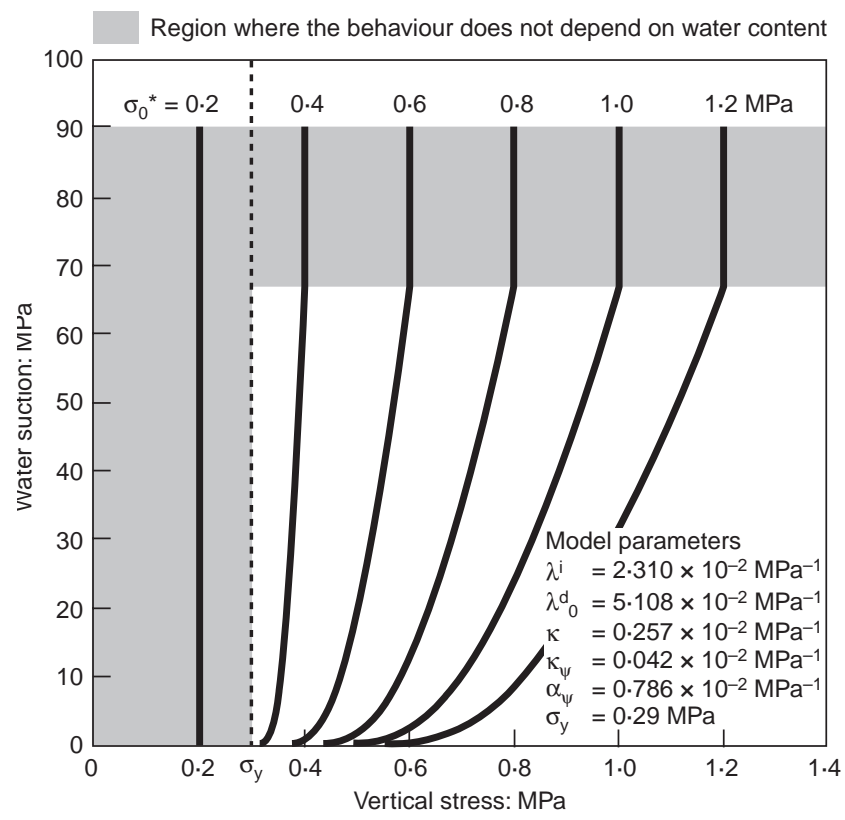

Fig. 15. Total suction formulation. Yield surface for different values of the hardening parameter $\sigma_{0}^{*}$. Pancrudo rockfill

\section{Discussion of experimental data and comparison with model predictions}

A physical interpretation was given to the nature of total suction in rockfill materials when the test procedure was discussed (Fig. 5): the sum of matric plus osmotic suction components in the liquid water contained in the rock pores and in thermodynamic equilibrium with the specimen's gas phase. Its use as a fundamental variable in a constitutive model for rockfill compressibility may seem somewhat arbitrary and meaningless if considered from a pure mechanical point of view. However, from a thermodynamical point of view, total suction can be considered as a measure of the chemical potential of water. Taking pure water at a given constant temperature and having a flat gas-liquid interphase as a reference state, the chemical potential of liquid water, $\mu_{\mathrm{w}}$, can be simply related to total suction by (Navarro, 1997)

$$
\mu_{\mathrm{w}}-\mu_{\mathrm{w} 0}=-v \psi=-v(s+\pi)
$$

where $\mu_{\mathrm{w} 0}$ is the chemical potential of the reference state.

Under isothermal conditions $\mu_{\mathrm{w}}$ and $\psi$ become proportional because the molar volume, $\nu$, is constant. As discussed when presenting the conceptual model, for a given rock under constant $K$, the rate of the stress corrosion reaction depends on the chemical potential of water (Wiederhorn et al., 1982): that is, it becomes faster the higher $\mu_{\mathrm{w}}$ is (compare equations (2), (3) and (18)). Considering the proposed conceptual model, an increase in the reaction rate would produce not only an increase in the rockfill strain rate but also a net increase in strain that is not related to an increase in stress: that is, a collapse strain. Confirming the previous discussion, the experimental data presented in this paper (Fig. 11) show a close correlation between strain and total suction (a good experimental correlation with RH could obviously be established, but it leads to a more complicated mathematical formulation). Note that owing to the negative sign in equation (18) a decrease in suction implies an increase in the chemical potential of water and hence an increase in the crack propagation velocity. Consistently, it can be observed in Fig. 11 that a reduction of suction during the wetting path causes an increment in strain to occur.

In terms of the proposed model, samples of the same material (same grain size distribution, same particle mineralogical composition and same particle shape) but having different initial void ratios are treated as different materials, and a new set of parameters should in principle be determined for each different material initial density. Model parameters may be 
derived in a straightforward manner from experimental results. As an example, model parameters have been obtained for the Pancrudo slate specimens tested on the basis of the experimental data from tests 1, 3 and 4. Experimental data from tests 2 and 5 will be used as verification tests in order to check the ability of the model to reproduce more general non-trivial paths in the vertical stress-total suction space.

The slope of the compression lines for the very dry specimen (test 3) and for the saturated one (test 1) (Fig. 6(b)) provide data for the determination of $\lambda^{\mathrm{i}}$ and $\lambda_{0}^{\mathrm{d}}$. A theoretical definition of the clastic yield stress was given as the threshold stress value that marks the onset of the clastic yielding. This may be interpreted as the change in the slope of the normal compression line of the saturated material (test 1) shown in Fig. 6(b). However, it is more suitable to obtain it from the following expression, in terms of the measured total collapse strain $\varepsilon_{\text {collapse }}$ due to flooding a very dry sample (test 3 ) under constant stress $\sigma_{0}$, the measured total expansion strain $\varepsilon_{\text {expansion }}$ due to flooding under low applied stress (test 1) and the previously determined parameter $\lambda_{0}^{\mathrm{d}}$ :

$$
\sigma_{\mathrm{y}}=\sigma_{0}-\frac{\varepsilon_{\text {collapse }}+\varepsilon_{\text {expansion }}}{\lambda_{0}^{\mathrm{d}}}
$$

The elastic index, $\kappa$, is directly obtained from unloadingreloading paths (test 3) (Fig. 6(b)). The water content or suction-based expansion/compression indexes $\left(\kappa_{\mathrm{w}}\right.$ or $\left.\kappa_{\psi}\right)$ require the performance of swelling (or drying) tests at constant stress (test 1). Finally, the parameter $\alpha_{\mathrm{w}}$ (or $\alpha_{\psi}$ ) may be obtained from collapse tests conducted under water content or suction control (test 4, Figs 10 and 11). Model parameters computed from the test results are summarized in Table 2 for both the water content formulation and suction formulation.

Tests results from which parameters were computed (1, 3 and 4) are reproduced by the model in Fig. 16 together with the experimental data. Model predictions computed for the stress-

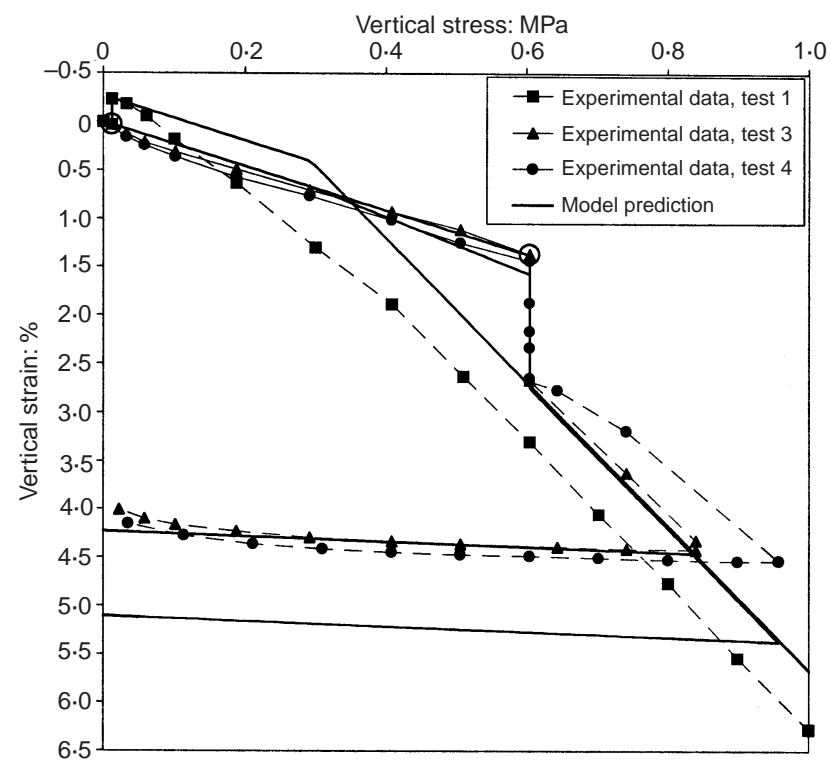

Fig. 16. Reproduction of tests 1,3 and 4 (from which model parameters were derived) with the proposed suction-based constitutive model. Open circles indicate specimen flooding water content and stress-total suction paths followed by tests 2 and 5 are plotted in Figs 17(a) and 17(b) together with the experimental data. The general behaviour of the material is satisfactorily described by the suction and water content based models, although only the former one is plotted in Figs 14 and 15. In general, the slope of the normal compression lines at the three different applied suction values $(100$ and $0 \mathrm{MPa}$ in test 2 , and $5 \mathrm{MPa}$ in test 5 ) is reasonably well reproduced. The main

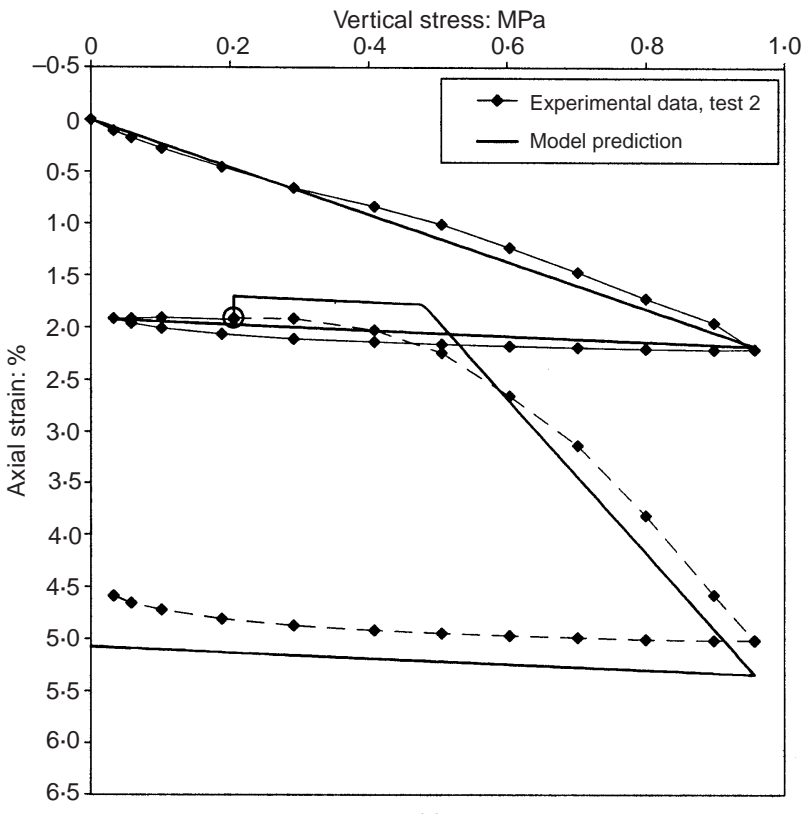

(a)

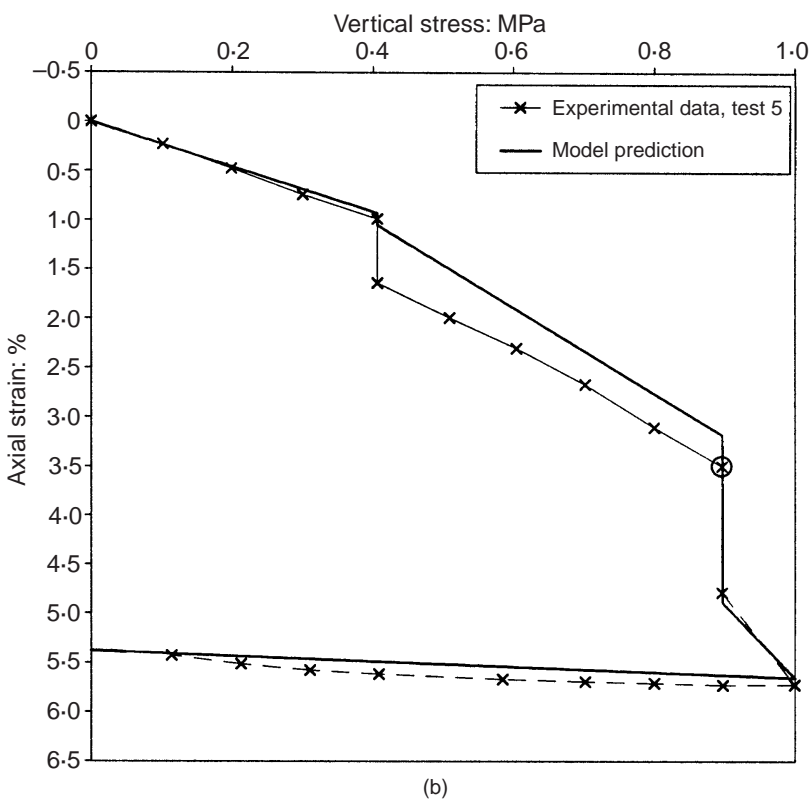

Fig. 17. Comparison between experimental data obtained for the Pancrudo slate in (a) one-dimensional compression test 2 , (b) onedimensional compression test 5 , and prediction of suction based model. Open circles indicate specimen flooding

Table 2. Model parameters for water content and suction formulation

\begin{tabular}{l|c|c|c|c|c|c}
\hline \multicolumn{1}{c|}{ Parameter } & $\lambda^{\mathrm{i}}: \mathrm{MPa}^{-1}$ & $\lambda_{0}^{\mathrm{d}}: \mathrm{MPa}^{-1}$ & $\alpha_{\mathrm{w}}$ or $\alpha_{\psi}: \mathrm{MPa}^{-1}$ & $\sigma_{\mathrm{y}}: \mathrm{MPa}$ & $\kappa: \mathrm{MPa}^{-1}$ & $\kappa_{\mathrm{w}}$ or $\kappa_{\psi}: \mathrm{MPa}^{-1}$ \\
\hline$w$ formulation & $2 \cdot 310 \times 10^{-2}$ & $5 \cdot 108 \times 10^{-2}$ & $2 \cdot 622 \times 10^{-2}$ & $0 \cdot 290$ & $0 \cdot 257 \times 10^{-2}$ \\
$\psi$ formulation & & & $0 \cdot 786 \times 10^{-2}$ & & $0 \cdot 139 \times 10^{-2}$ \\
\hline
\end{tabular}


discrepancies lie in the position of the normal compression line for the saturated material $(\psi=0 \mathrm{MPa})$ and, to a lesser extent, for the partially wetted material $(\psi=5 \mathrm{MPa})$. Experimental data show some dispersion in this regard (see Fig. 6(b)), and since a unique set of model parameters is used, discrepancies between model results and experimental data are unavoidable. Collapse deformation in test 5 during partial wetting under a $0.4 \mathrm{MPa}$ vertical stress is underpredicted by the model (Fig. 17(b)). This collapse was measured for a vertical stress that is close to the clastic yield stress, identified in tests 1,3 and 4 as $\sigma_{\mathrm{y}}=0.29 \mathrm{MPa}$. In the model, collapse starts gradually when $\sigma>\sigma_{\mathrm{y}}$ and remains small when the confining stress $\sigma$ is close to $\sigma_{\mathrm{y}}$. The fact that the collapse strain predicted at $\sigma=0.9 \mathrm{MPa}$ is closer to the measured value suggests that collapse strains change with stress in a more complex manner than suggested by the model. It is believed, however, that the relatively simple formulation developed is capable of reproducing the tests performed in a satisfactory way overall.

\section{CONCLUSIONS}

In the present paper, compressibility and collapse features of rockfill have been interpreted in terms of rock basic properties and fracture propagation phenomena. A conceptual model based on the subcritical crack growth mechanism is proposed. It gives a comprehensive explanation for the occurrence of time-dependent and collapse strains, and for the influence of water on rockfill behaviour.

An intrinsic time-dependent behaviour of rockfill emerges from the proposed conceptual model, since the subcritical crack propagation velocity, which depends simultaneously on contact stresses and rock water content, determines the deformation rate of rockfill.

An oedometer with relative humidity control was developed, and a test programme was carried out on a rockfill-type material (quartzitic slate of Cambric origin). The main conclusion of this test programme is that bringing the relative humidity to $100 \%$ within the rockfill voids leads to a collapse strain equal to that observed in flooded specimens. Therefore any situation leading to a change in water content of the rock particles is enough to cause collapse deformations and also to increase the material compliance against further loading. This conclusion is consistent with the rain-induced settlements observed in rockfill dams and embankments.

A macroscopic elastoplastic model for rockfill compression has been developed for moderate stress levels. It considers two stages of behaviour: particle rearrangement, in which only an instantaneous deformation mechanism acts; and clastic yielding, where both instantaneous and time-dependent deformation mechanisms may act. A threshold confining stress, which becomes a model parameter, marks the transition from the particle rearrangement to the clastic yielding stage. It has also been found that the time-dependent deformation mechanism depends on the water content of rock particles. The intensity of this yielding mechanism is a maximum for saturated rock particles, and tends to zero for a very dry material. Therefore in dry rockfills only the instantaneous yielding mode will be present.

A linear dependence of rockfill compressibility with the logarithm of water content has been measured in the tests performed. A yield locus in the oedometer plane (axial stress against water content) has been derived in closed form. An alternative total suction-based formulation has also been presented. It is conceptually similar to the water content formulation, and both are connected through the water retention characteristics of the rock. The model has been completed by the derivation of the strain hardening law.

Six model parameters describe the compression behaviour of rockfill under oedometer (or isotropic) conditions. These materials parameters have a clear physical meaning, and they are easy to obtain from compressibility tests. A set of constitutive parameters has been obtained for the rockfill tested, and model predictions have been compared with measured test results.

\section{ACKNOWLEDGEMENTS}

The authors gratefully acknowledge the financial support given to the first author by the Universidad Nacional de San Juan (Argentina) during the research work reported in this paper.

\section{NOTATION}

$F$ yield function

$K$ fracture toughness

$K_{\mathrm{c}}$ stress intensity factor

$p_{\text {atm }}$ atmospheric pressure

$s$ matric suction

$\pi$ osmotic suction

$\psi$ total suction

$\mu_{\mathrm{w}}$ chemical potential of water

$\mu_{\mathrm{w} 0}$ chemical potential of water at reference state

$V$ crack propagation velocity

$T$ absolute temperature

$R$ gas constant

$v$ molar volume of water

$\mathrm{RH}$ relative humidity

$V_{0}, E \ddagger, b$ experimental constants in crack propagation velocity expression

$w, w_{\mathrm{i}}$ gravimetric water content, initial gravimetric water content

$\alpha_{\mathrm{w}}$ compressibility parameter (water-content-based formulation)

$\alpha_{\psi}$, compressibility parameter (suction-based formulation)

$\chi_{\mathrm{w}}$ experimental coefficient relating collapse strain with water content

$\chi_{\psi}$ experimental coefficient relating collapse strain with suction

$\varepsilon$ total vertical strain

$\varepsilon^{\mathrm{i}}$ instantaneous total vertical strain component

$\varepsilon^{\mathrm{d}}$ time dependent total vertical strain component

$\varepsilon^{\mathrm{e}} \quad$ elastic vertical strain due to stress changes

$\varepsilon^{\mathrm{w}} \quad$ elastic vertical strain due to water content changes

$\varepsilon^{\psi} \quad$ elastic vertical strain due to suction changes

$\varepsilon^{\mathrm{p}} \quad$ plastic vertical strain

$\varepsilon_{\text {collapse }} \quad$ collapse strain due to flooding under constant stress $\sigma_{0}$

$\varepsilon_{\text {expansion }}$ expansion strain due to flooding under zero applied stress

$\lambda^{\mathrm{i}}$ normal compressibility index when only the IDM is active

$\left(\lambda^{\mathrm{i}}+\lambda^{\mathrm{d}}\right)$ normal compressibility index when both IDM and TDM deformation mechanisms are active

$\lambda_{0}^{\mathrm{d}}$ maximum clastic compressibility index (for $w=w_{0}$ or $\psi=0$ )

$\kappa$ slope of the URL

$\kappa_{\mathrm{W}} \quad$ water-content-based expansion/compression index

$\kappa_{\psi} \quad$ suction-based expansion/compression index

$\sigma$ oedometer vertical stress

$\sigma_{\mathrm{y}}$ clastic yield stress (stress threshold that marks the onset of particle breakage)

$\sigma_{0} \quad$ yield vertical stress

$\sigma_{0}^{*} \quad$ model hardening parameter

IDM instantaneous deformation mechanism

TDM time-dependent deformation mechanism

\section{REFERENCES}

Atkinson, B. K. (1984). Subcritical crack growth in geological materials. J. Geophys. Res. 89, No. B6, 4077-4114.

Atkinson, B. K. \& Meredith, P. G. (1987). The theory of subcritical crack growth with applications to minerals and rocks. In Fracture mechanics of rock (ed. B. K. Atkinson) London: Academic Press. pp. 111-166

Bazant Z. P. \& Planas, J. (1998). Fracture and size effect in concrete and other quasibrittle materials. CRC Press, New York.

Broek, D. (1985). Elementary engineering fracture mechanics, 4th edn. Dordrecht: Martinus Nijhoff Publishers.

Clements, R. P. (1981). The deformation of rockfill: inter-particle behaviour, bulk properties and behaviour in dams. $\mathrm{PhD}$ thesis, Faculty of Engineering, King's College, University of London.

Coussy, O. (1995). Mechanics of porous continua. Chichester: John Wiley \& Sons. 
De Alba, E. \& Sesana, F. (1978). The influence of expansive minerals on basalt behaviour. Proceedings of the international congress of engineering geology, Madrid, pp. 107-116.

Delgado Rodriguez, J., Veiga Pinto, A. \& Maranha das Neves, E. (1982). Rock index properties for prediction of rockfill behaviour, Memória $\mathrm{N}^{\mathrm{o}}$ 581. Lisbon: Laboratório Nacional de Engenharia Civil.

Freiman, S. W. (1984). Effects of chemical environments on slow crack growth in glasses and ceramics. J. Geophys. Research 89, No. B6, 4072-4076.

Fumagalli, E. (1969). Tests on cohesionless materials for rockfill dams. J. Soil Mech. Found. Engng Div., ASCE 95, No. SM1, 313-330.

Laidler, K. J. (1987). Chemical kinetics, 3rd edn. HarperCollins Publishers, New York.

Marachi, N. D., Chan, C. K., Seed, H. B. \& Duncan, J. M. (1969). Strength and deformation characteristics of rockfill materials, Department of Civil Engineering, Report No. TE-69-5. University of California.

Marsal, R. J. (1973). Mechanical properties of rockfill. In Embankment dam engineering. Casagrande volume (eds R. C. Hirschfeld \& S. J. Poulos), John Wiley \& Sons, New York, 109-200.

Marsal, R. J., Arellano, L. R., Guzmán, M. A. \& Adame, H. (1976). El Infiernillo. Behavior of dams built in Mexico. Mexico: Instituto de Ingeniería, UNAM.

McDowell, G. R. \& Bolton, M. D. (1998). On the micromechanics of crushable aggregates. Géotechnique 48, No. 5, 667-679.

Michalske, T. A. \& Freiman, S. W. (1982). A molecular interpretation of stress corrosion in silica. Nature 295, 511-512.

Murakami, Y. (1987). Stress intensity factors handbook. Oxford: Pergamon Press.

Navarro, V. (1997). Modelo del comportamiento mecánico e hidráulico de suelos no saturados en condiciones no isotermas. D. thesis, Department of Geotechnical Engineering and Geosciences, Universitat Politecnica de Catalunya, Barcelona, Spain.

Naylor, D. J., Maranha, J. R., Maranha das Neves, E. \& Veiga Pinto, A. A. (1997). A back-analysis of Beliche Dam. Géotechnique 48, No. $2,221-233$
Nobari, E. S. \& Duncan, J. M. (1972). Effect of reservoir filling on stresses and movements in earth and rockfill dams, Department of Civil Engineering, Report No. TE-72-1. University of California.

Penman, A. D. M. \& Charles, J. A. (1976). The quality and suitability of rockfill used in dam construction. Dams and embankments, Practical Studies from the BRE. London: The Construction Press, 6, $72-85$.

Penman, A. D. M. (1992). Rockfill for embankment dams. In Raul J. Marsal Volume (eds E. Ovando, G. Auvinet, W. Paniagua \& J. Díaz), pp. 303-327. Mexico: Sociedad Mexicana de Mecánica de Suelos, A.C.

Pestana, J. M. \& Whittle, A. J. (1995). Compression model for cohesionless soils. Géotechnique 45, No. 4, 611-631.

Sammis, C. G. (1997). Fractal fragmentation and frictional stability in granular materials. Proceedings IUTAM symposium on mechanics of granular and porous materials (eds N. A. Fleck and A. C. F. Cocks), Dordrecht: Kluwer, 23-34.

Sowers, G. F., Williams, R. C. \& Wallace, T. S. (1965). Compressibility of broken rock and settlement of rockfills. Proc. 6th ICSMFE, Montreal, 2, 561-565.

Terzaghi, K. (1960). Discussion on Salt Springs and Lower Bear River dams. Trans. ASCE 125, pt 2, 139-148.

Veiga Pinto, A. A. (1983). Previsao do comportamento estrutural de barragens de enrocamento. $\mathrm{PhD}$ thesis, Laboratório Nacional de Engenharia Civil, Lisbon.

Vutukuri, V. S. \& Lama, R. D. (1978). Handbook on mechanical properties of rocks. Claustahl: Trans Tech Publications.

Wiederhorn, S. M., Fuller, E. R. \& Thomson, R. (1980). Micro-mechanisms of crack growth in ceramics and glasses in corrosive environments. Met. Sci. 14, 450-458.

Wiederhorn, S. M., Freiman, S. W., Fuller, E. R. \& Simmons, C. J. (1982). Effects of water and other dielectrics on crack growth. J. Mater. Sci. 17, 3460-3478.

Yamamuro, J. A., Bopp, P. A. \& Lade, P. V. (1996). One-dimensional compression of sands at high pressures. J. Geotech. Engng Div., ASCE 122, No. 2, 147-154. 